
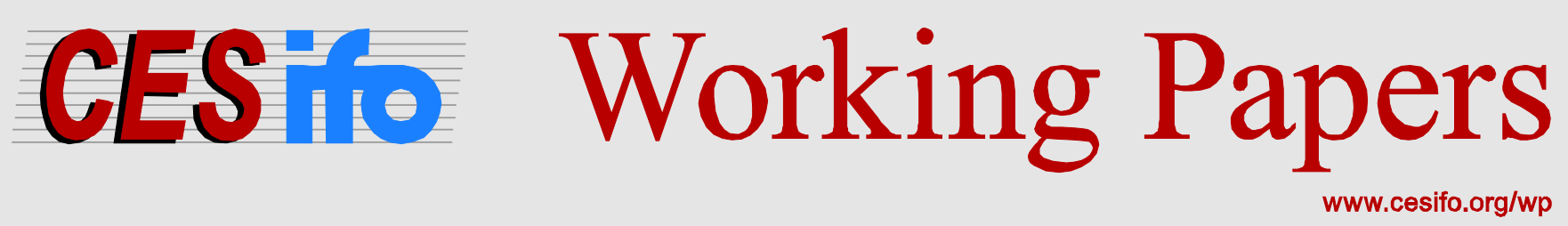

\title{
Temptation in Vote-Selling: Evidence from a Field Experiment in the Philippines
}

\author{
Allen Hicken \\ Stephen Leider \\ Nico Ravanilla \\ Dean Yang
}

CESIFO WORKING PAPER NO. 4828

CATEGORY 13: BEHAVIOURAL ECONOMICS

JUNE 2014

Presented at CESifo Area Conference on Behavioural Economics, October 2013

An electronic version of the paper may be downloaded

- from the SSRN website:

- from the RePEc website:

www.SSRN.com

- from the CESifo website:

www.RePEc.org

www.CESifo-group.org/wp

\section{CESifo}




\title{
Temptation in Vote-Selling: Evidence from a Field Experiment in the Philippines
}

\begin{abstract}
We test the predictions of a behavioral model of transactional electoral politics in the context of a randomized anti-vote-selling intervention in the Philippines. We model selling one's vote as a temptation good: it creates positive utility for the future self at the moment of voting, but not for past selves who anticipate the vote-sale. We also allow keeping or breaking promises regarding vote-selling to affect utility. Voters who are at least partially sophisticated about their vote-selling temptation can thus use promises not to vote-sell as a commitment device. An invitation to promise not to vote-sell is taken up by a majority of respondents, reduces vote-selling, and has a larger effect in electoral races with smaller vote-buying payments. The more effective promise treatment reduces vote-selling in the smallest-stakes election by 10.9 percentage points. Inviting voters to make another type of promise - to accept vote-buying payments, but to nonetheless "vote your conscience" - is significantly less effective. The results are consistent with voters being partially (but not fully) sophisticated about their voteselling temptation.
\end{abstract}

JEL-Code: D030, D720, O120.

Keywords: vote-selling, vote-buying, temptation, self-control, commitment, elections, political economy, Philippines.

\author{
Allen Hicken \\ Department of Political Science \\ University of Michigan / USA \\ ahicken@umich.edu \\ Nico Ravanilla \\ Department of Political Science \& \\ Gerald R. Ford School of Public Policy \\ University of Michigan / USA \\ rnico@umich.edu
}

\author{
Stephen Leider \\ Stephen M. Ross School of Business \\ University of Michigan / USA \\ leider@umich.edu \\ Dean Yang* \\ Department of Political Science \& \\ Gerald R. Ford School of Public Policy \\ University of Michigan / USA \\ deanyang@umich.edu
}

*corresponding author

May 2014

We thank Joma Gonzalez (Innovations for Poverty Action) for unparalleled field management, Vibha Mehta for her contributions to the field work and analysis, and seminar participants at Georgia Institute of Technology, Simon Fraser University, University of British Columbia, the World Bank, and Georgetown University. This study was made possible by funding from the MCubed program at the University of Michigan. 


\section{Introduction}

Vote-buying and vote-selling are pervasive phenomena in many developing democracies. While there is some debate about the consequences of the buying and selling of votes, there is a consensus that transactional electoral politics brings with it a host of costs. For example, vote-buying and other forms of clientelism can undermine or even reverse the standard accountability relationship that is central to democracy (Stokes 2005; Lyne 2007; Kitschelt et. al, 2010; Hicken 2011; Stokes et. al. 2013.) Vote-buying also hampers the development of and trust in the political institutions necessary for democratic development and consolidation (Lyne 2007; Stokes 2005; Graziano 1973; Kitschelt et. al. 2010; Desposato 2007). Finally, vote-buying and other forms of clientelism are associated with larger public deficits and public sector inefficiencies (Keefer 2006; Keefer 2007; Hicken and Simmons 2008), and higher levels of corruption (Singer 2009; Keefer 2007; Kitschelt 2007; Kitschelt et. al. 2010).

Because of these potential inimical effects, governments, NGOs and international donors have directed significant attention and resources towards combating vote-buying and vote-selling. Some strategies focus on the demand side of the equation-making it more difficult for politicians (or vote-buyers) to offer money in exchange for a vote. However, such strategies often fall victim to poor implementation and enforcement. As a result, a major focus of anti-vote-buying efforts has been on vote-sellers. Whether organized by governmental election commissions, or by concerned NGOs, campaigns to reduce the supply of votes available for purchase are common worldwide. Voter-focused campaigns against vote-selling tend to fall into two categories. The first type of campaign urges voters to avoid taking vote-buying payments at all. Voters may be asked to make promises or sign pledges to simply eschew taking money from politicians or their agents prior to elections. A second common approach seeks to subvert vote-buying by encouraging voters to take the money being offered, but nonetheless "vote their conscience." For example, Cardinal Sin, Archbishop of Manila, famously advised voters to "take the bait but not the hook" (Schaffer 2005). ${ }^{1}$

\footnotetext{
${ }^{1}$ For examples of both types of campaigns, see Callahan (2000), Schaffer (2005), Guiang (2013), and Geronimo (2013).
} 
Motivated by both the negative consequences of transactional electoral politics, and by the prevalence of anti-vote-selling efforts, in this paper we seek to deepen our understanding of the economics and psychology of individual vote-selling decisions. A number of questions are of general interest. What is the efficacy of anti-vote-selling campaigns? Can simple promises - such as the ones elicited from voters in anti-voteselling campaigns - affect vote-selling behavior? If so, why might voters make such promises? Does the impact of promises differ by type of promise (e.g., "I won't take money" vs. "I'll take money, but vote my conscience")? Might some types of promises actually increase the incidence vote-selling?

We shed light on these questions via theoretical modeling combined with a randomized controlled trial. We present a simple behavioral model where selling one's vote is a temptation good: it creates positive utility for the future self at the moment of voting, but not for past selves who anticipate the sale of the vote. In addition, voters can make promises in advance of elections regarding whether or not they will sell their votes, and gain (lose) utility when they keep (break) such promises. We also allow for the possibility that voters may not be fully sophisticated about their vote-selling temptation. Specifically, when deciding whether to accept a gift from a candidate, they may underestimate how much utility the future self will gain from voting for the candidate who provided the gift (said another way, they underestimate the impact of accepting votebuying payments today on their propensity to vote for the vote-buying candidate in the future.) The model also implies that voters who are at least partially sophisticated about their vote-selling temptation can use promises not to sell their votes as a commitment device.

We test the model's predictions in the context of a randomized controlled trial of an anti-vote-selling intervention in Sorsogon City, Philippines. We randomly assigned voters to a control group or to one of two treatment groups. In the Promise 1 treatment, we invited voters to promise not to take vote-buying payments at all. In the Promise 2 treatment, we invited voters to promise that if they did take vote-buying payments, they would nevertheless "vote their conscience." The two kinds of promises were designed to mirror the types of promises elicited in anti-vote-selling campaigns. 
We estimate the impacts of promise treatments on a proxy for vote-selling: voteswitching, which we define as voting for a candidate who was not rated one's favorite in a pre-election survey some weeks before. ${ }^{2}$ While examining vote-switching is an indirect way of getting at vote-selling, vote-switching is self-reported, which raises concerns about social desirability bias: respondents could respond to the promise treatments by falsely maintaining consistency between their pre-election ratings and their post-election voting reports. Such biased reporting could lead us to spuriously find that the promise treatments reduce vote-switching.

Our results provide a reasonably strong indication that social desirability bias is not a significant concern in our setting. Support for this claim comes from comparisons of the treatment effects of Promise 1 ("Don't take the money") on vote-switching across electoral races. ${ }^{3}$ One would expect social desirability bias to be constant across electoral races, or increasing in the importance of the race. In our setting, if there were only social desirability bias and no "true" treatment effects, this would mean that we should find larger (negative) treatment effects for the mayor and vice-mayor races, compared to the city council race. As it turns out, we find the opposite to be true: the Promise 1 treatment effects on voteswitching, while negative, are very close to zero in the two most important electoral races that we examine (the elections for mayor and vice-mayor.) By contrast, we find much larger negative effects on vote-switching in the city council election, the least important of the races. We conclude from this comparison that our treatment effect estimates are minimally biased (if at all) by intentional misreporting.

We estimate that the Promise 1 treatment reduced vote-switching (and therefore vote-selling) in the race involving smaller vote buying payments (the city council race) by 10.9 percentage points. Compared to the city-council vote-switching rate of 47.1 percent in the control group, this is a large effect, given that vote-switching can occur for reasons other than vote-selling. As mentioned previously, the impacts of the Promise 1 treatment

\footnotetext{
2 Individuals can be "vote-switchers" for many reasons aside from vote-selling (such as learning new information about candidates), but, given random assignment, the promise treatments should only affect vote-switching via changes in vote-selling.

${ }^{3}$ As we discuss further below, analogous comparisons across races for Promise 2 treatment effects are not as revealing of the extent of social desirability bias because Promise 2 , in principle, can actually raise voteswitching.
} 
on vote-switching in the more important races (mayor and vice-mayor) are close to zero and are not statistically significant.

We also test our results against the predictions of our theoretical model, which involve statistical tests of pairwise differences in treatment effects across promise types (but within electoral races), and across races (but within promise types). We find that the Promise 1 treatment has a more negative effect on vote-switching than does the Promise 2 treatment. This pattern of results supports the partial sophistication case of the theoretical model, wherein voters are only partially aware of their vote-selling temptation. This worse performance of Promise 2 must come from respondents who would not have accepted money under the control treatment (i.e. with no promise), but who (incorrectly) believe they can accept money without changing their vote due to making the promise. By contrast, a fully sophisticated voter correctly anticipates his temptation, so will not make this mistake. Fully naïve voters cannot increase their uptake of gift offers, since they would accept money in the control treatment as well.

We also find that the promise treatments reduce vote-switching more for races with lower vote-buying payments (the city council race) than in the higher-money races (the mayor and vice-mayor races). This finding confirms the theoretical predictions for Promise 1 treatment, and is also among the possible outcomes for the Promise 2 treatment.

Our research is related to work on electoral malpractices more generally. Existing research has established, via natural experiments in a variety of contexts, that electoral malpractices have material influence on election outcomes (Golden and Tiwari 2009, Acemoglu, Robinson, and Santos 2009, Baland and Robinson 2009). On the specific topic of vote-selling, research has shown it to be more prevalent among poor voters (Scott 1969, Stokes 2005, Blaydes 2006, Bratton 2008), and that parties, candidates and brokers are often strategic regarding which populations they target for vote-buying (Stokes et. al. 2013). Khemani (2013) finds that the extent of vote-buying is negatively correlated with public health service delivery across municipalities in one Philippine province. Finan and Schechter (2012) find that vote-buying payments in rural Paraguay are targeted to "reciprocal" individuals (as measured in an artefactual field experiment), suggesting that vote-buying exploits informal norms of reciprocity. Vicente (forthcoming) conducted a randomized controlled trial of an anti-vote-selling intervention, finding that it raised the 
vote share of incumbents, consistent with challengers' use of vote-buying to overcome incumbency advantages.

In its focus on the real-world impact of promises, this paper is also related to recent work from behavioral psychology and economics that shows that promises and other informal agreements can substantially change behavior and lead to more socially efficient outcomes by changing social norms (Charness and Dufwenberg 2006; Vanberg 2008; Kessler and Leider 2012; Krupka, Leider and Jiang 2013). Shu et al (2012) show that the form of promise elicitation affects honesty in reporting of information in auto insurance applications. We also have a clear connection to research on temptation goods (Banerjee and Mullainathan 2010, Fudenberg and Levine 2006, Gul and Pesendorfer 2001) and on self-control problems (Laibson 1997, Ashraf et al 2006, Duflo et al 2011, Kaur et al 2013).

In the next section we describe the experimental context and vote-buying practices. In Section 3 we present a behavioral model of vote-selling. In Section 4 we describe the data collection and the experimental design. Section 5 discusses the proxy measure of vote-selling and the regression specification. Section 6 presents the empirical results, and Section 7 concludes.

\section{Context and Overview of Vote-Buying}

The experiment was conducted in Sorsogon City, Sorsogon Province, Philippines. Sorsogon Province is located at the southern tip of Luzon island, roughly 12 hours by road from the national capital, Manila. Sorsogon City, with a population of roughly 150,000, is the provincial capital, and is slightly below the median across Philippine municipalities in terms of economic development. With a municipal poverty rate of $35 \%$, it is slightly worse than the median (the $45^{\text {th }}$ percentile, to be exact) poverty rate among Philippine municipalities. ${ }^{4}$

We study voting behaviors in the 2013 elections for Sorsogon City municipal positions (mayor, vice-mayor, and city council). As in many other parts of the Philippines, vote-buying is widespread in our study location. We define vote-buying as the offer of resources by political campaigns to individuals or households in order persuade them to

\footnotetext{
${ }^{4}$ Poverty rates are from 2003. The Philippines' overall poverty incidence is $29 \%$ (National Statistical Coordination Board 2009).
} 
vote for a particular candidate. This definition is consistent with the definitions elsewhere in the literature (e.g. Stokes et. al. 2013, Vicente forthcoming).

Most vote buying in Sorsogon City occurs in the week leading up to election day. Using voter lists each campaign has developed, candidate representatives approach households directly, offering money or goods in exchange for their vote. Based on observations of our project field staff, vote-buying payments differed substantially across races. In the mayor and vice-mayor races, payments typically amounted to 250 to 500 Philippine pesos, while those for city council were in the range of 20 to 100 pesos. $^{5}$

Vote buying is done systematically and strategically. Typically, each voter in a household will be offered a packet with their name on it, and campaigns track who accepted and who did not. Payments are targeted at likely supporters, followed by those viewed as uncommitted. Few vote buying resources are expended on likely supporters of other candidates. While unaffiliated voters may receive offers of money from multiple rival candidates, most voters receive offers from only one candidate. Candidates may also engage in a second round of vote buying if they learn that a challenger is offering more money than they are.

Campaigns seek to ensure that voters clearly associate the gift with their candidate. For example, the candidate's flyer may be stapled to packages of food handed out to voters or cash may be attached to flyer or letter from the candidate. Most commonly, candidates distribute money attached to a sample ballot, and encourage voters to take the ballots with them to the polls as a guide. The sample ballot includes not just the candidate's name, but also allied candidates from other races up and down the ticket. For further background, including images of sample ballots, please see Online Appendix A.

\section{Theoretical Model}

We describe here a simple model of vote selling and the impact of promises not to sell one's vote. We will focus here on intuition and results, and discuss additional details in the appendix. We take as a starting point the findings of Finan and Schechter (2012) that vote-buying operates through a reciprocity channel. However, we model a voter's inclination to reciprocate a candidate's gift by through voting as a temptation, rather than

\footnotetext{
${ }^{5}$ One US dollar was worth roughly 41 Philippine pesos at the time of the study.
} 
an intrinsic part of the voter's utility. If the reciprocity of vote-selling was a preference of the voter, then the promises we study can only have a beneficial effect, and the promise to "take money but vote your conscience" (Promise 2) would dominate the promise not to accept money (Promise 1), both in terms of uptake and in effect on voting. By modeling vote-selling as a temptation problem, we allow for Promise 2 to have either a positive or negative effect, and to be more or less effective than Promise 1.

There are two candidates, Candidate 1 and Candidate $2 .{ }^{6}$ The voter has an intrinsic value $\mathrm{v}_{\mathrm{i}}$ for voting for Candidate $\mathrm{i}$. WLOG let $\mathrm{v}_{1}>\mathrm{v}_{2}$. At time $\mathrm{t}=1$, each Candidate $\mathrm{i}$ offers the voter a "gift" of value $g_{i} \geq 0$, which he may accept or reject. Since we are interested in vote-switching, the voters of interest will be those voters who receive a gift from Candidate 2 (their non-favored candidate). ${ }^{7}$ We model the influence of these gifts on the voter's voting decision at time $t=2$ as a self-control problem. At the time of voting, the voter receives psychic utility $\varphi^{*} \mathrm{~g}_{\mathrm{i}}$ for voting for Candidate $\mathrm{i}(\varphi$ measures intrinsic reciprocal motivation, i.e. how quickly utility increases with the size of the gift. $)^{8}$ Hence, the $t=2$ self has utility from voting for Candidate $i$ after having received gifts $g_{1}$ and $g_{2}$ of:

$$
\mathrm{U}^{2}{ }_{\mathrm{i}}=\mathrm{v}_{\mathrm{i}}+\varphi^{*} \mathrm{~g}_{\mathrm{i}}+\left(\mathrm{g}_{1}+\mathrm{g}_{2}\right)
$$

Given these preferences, if Candidate 2 gives the Voter (and he accepts) a gift that is sufficiently larger than the gift from Candidate 1, he can "buy" the voter's vote. A voter will "switch" his vote to Candidate 2 (i.e. vote against his intrinsic preferences) if his intrinsic reciprocity is sufficiently strong:

$$
\varphi\left(\mathrm{g}_{2}-\mathrm{g}_{1}\right)-\left(\mathrm{v}_{1}-\mathrm{v}_{2}\right)>0
$$

Hence, vote-selling is more likely when there is a larger difference in the gifts given, when the voter feels more reciprocal towards gift-giving candidates, and when the underlying difference in intrinsic preferences is smaller.

Since we are modeling reciprocity-based vote switching as a temptation, at the time of accepting money from candidates the $\mathrm{t}=1$ self does not feel reciprocal - he values only the intrinsic value of voting and the consumption value of receiving money:

\footnotetext{
${ }^{6} \mathrm{We}$ focus on two candidates for ease of exposition. With multiple candidates there will be one alternative candidate that is the most tempting to switch to (from a combination of large gift and/or high intrinsic value), so the analysis will be similar to the two candidate case.

${ }^{7}$ We consider the more general case where the voter may also receive a gift from Candidate 1 , his favored candidate. Many voters receive only one gift offer, so this would be represented by having $g_{2}>0$ and $g_{1}=0$. ${ }^{8}$ Note that we assume that this reciprocal desire to vote for a gift-giver does not change the underlying voting preferences of the voter (otherwise asking voters to "vote your conscience" wouldn't affect their behavior).
} 


$$
\mathrm{U}^{1}{ }_{\mathrm{i}}=\mathrm{v}_{\mathrm{i}}+\left(\mathrm{g}_{1}+\mathrm{g}_{2}\right)
$$

Hence preferences at $\mathrm{t}=1$ reflect the "cold" state without temptation, while preferences at $\mathrm{t}=2$ reflect the "hot" state with temptation." We assume that the voter is may be (partially) sophisticated about his temptation - at time $\mathrm{t}=1$ the voter in the cold state believes his intrinsic reciprocity at $\mathrm{t}=2$ will be $\varphi^{\prime} \leq \varphi$.

\section{Promises}

With our experimental intervention, the voter is asked at time $t=0$ to promise not to sell his vote. Specifically, we ask some voters to promise not to accept money from candidates (Promise 1), and other voters to promise to "vote your conscience" even if they accept money (Promise 2). We describe here how these promises not to vote-sell affect utility. $^{10}$

At $\mathrm{t}=0$ the voter has the same "cold" state preferences as at $\mathrm{t}=1$. Additionally, we assume the voter receives psychic utility $\gamma$ for taking an action consistent with a promise, and receives disutility $\gamma$ for breaking a promise. ${ }^{11}$ This could reduce vote selling in two ways, depending on the promise. An effective promise not to accept money would make $\mathrm{g}_{1}=\mathrm{g}_{2}=0$, causing (1) to fail. A promise to vote one's conscience would lead to vote switching if

$$
\varphi\left(\mathrm{g}_{2}-\mathrm{g}_{1}\right)-\left(\mathrm{v}_{1}-\mathrm{v}_{2}\right)>2 \gamma
$$

Hence if a voter was only marginally willing to switch his vote, a promise might cause him not to switch.

We next consider more formally the conditions under which each promise will have an effect on vote selling. We will first discuss conceptually the fully sophisticated

\footnotetext{
${ }^{9}$ We also considered a simpler model where the voter does not have a self-control problem (i.e. he has stable preferences over time). In this case promises (of either kind) either reduce vote selling, or have no effect. We consider reciprocity as a self-control problem to allow the promise to vote your conscience to actually increase vote-selling.

${ }^{10}$ We note that both promises are consistent with existing anti-vote-selling messages and broader moral sentiments and norms. Our model is not intended to describe arbitrary promises.

${ }^{11}$ This is consistent with the results of Krupka, Leider and Jiang (2014) who show that making a promise to take a particular action increases the normative appropriateness of taking the agreed upon action, and decreases the appropriateness of all other actions. Many previous models of promise keeping include only the negative utility penalty for violating a promise (Chen et al 2008, Ellingsen and Johannesson 2004, Ozer et al 2011). For our purposes the key assumption is the positive utility for following a promise, otherwise no voter would make a promise. We include the negative utility penalty for violating the promise to maintain consistency with the previous literature, but we would obtain similar results without it. We make the two utility impacts of equal magnitude for simplicity.
} 
$\left(\varphi^{\prime}=\varphi\right)$ and fully naïve $\left(\varphi^{\prime}=0\right)$ cases to build intuition, and then formally consider the general model which includes these as special cases.

\section{Fully Sophisticated Voters}

As previously mentioned, fully sophisticated voters correctly anticipate the magnitude of their temptation to vote based on receiving gifts. Such a voter will always accept gifts from Candidate 1, and small gifts from Candidate 2 that will not affect his vote. For large gifts the value of the gift must outweigh the cost of changing his vote. Hence when there is no promise request, we expect vote switching in cases where candidates offer a large gift, and where voters have small preference differences between candidates compared to their reciprocity.

A fully sophisticated voter also correctly anticipates the effect of making a promise. Suppose a voter was going to accept both gifts and change his vote. For him to be willing to promise not to accept money, he must be willing to turn down both gifts in order to keep his promise, and must place higher utility on keeping his promise plus voting for his preferred candidate more than the value of the gifts. Similarly, to make the promise to vote his conscience, the utility of keeping his promise plus voting for his favorite candidate must exceed the value of the gift from 2. Hence both promises can reduce vote selling for sophisticated voters if the costs of violating a promise are sufficiently large.

\section{Naïve Voters}

Naïve voters do not expect to be tempted at all. Hence they will always accept any gift, and will change their vote if the gift from Candidate 2 is sufficiently large. Since the naïve voter does not expect to switch, and therefore does not expect the promise to affect his vote, he will make Promise 1 if the utility of the promise exceeds the value of both gifts alone (without voting utility.) However, once the promise is made it will be effective. A naïve voter will always make Promise 2 , since he thinks he will always be able to vote his conscience. He will then accept both gifts. He will ultimately keep his promise if the utility of keeping his promise is sufficiently strong, i.e. if (2) holds. Hence both promises can also be effective for naïve voters.

\section{Partially Sophisticated Voters}


We now consider the general case of a partially sophisticated voter ${ }^{12}-$ i.e. a voter who recognizes the reciprocal temptation he feels during voting, but underestimates its strength. Specifically, at times $\mathrm{t}=0$ and $\mathrm{t}=1$, the voter believes that his intrinsic reciprocity at $\mathrm{t}=2$ will be $\varphi^{\prime}$, with $0 \leq \varphi^{\prime} \leq \varphi$. As $\varphi^{\prime}$ approaches zero the voter will act more like a naïve voter, while as $\varphi^{\prime}$ approaches $\varphi$ the voter will act more like a fully sophisticated voter.

\section{No Promise}

A partially sophisticated voter will always accept a gift from Candidate 1, since that will only reinforce his candidate preferences. Whether he will accept a gift from Candidate 2 depends first on whether he thinks it will affect his vote. The voter will believe that accepting the gift will change his vote if:

$$
\varphi^{\prime}\left(g_{2}-g_{1}\right)-\left(v_{1}-v_{2}\right)>0
$$

A partially sophisticated voter will accept any gift that he does not expect to affect his vote, i.e. if (3) does not hold. ${ }^{13}$ He will accept a gift that he expects to change his vote if it is sufficiently large: $g_{2}>v_{1}-v_{2}$. Hence, as with the other cases discussed above, we expect more vote switching when candidate gifts are larger.

\section{$\underline{\text { Promise } 1}$}

We now consider what impact a promise not to accept money would have on a voter's behavior. We want to identify cases where the promise reduces vote selling, so we focus on the case where absent a promise the voter will accept the gift from Candidate 2 and switch his vote. There are two cases where this occurs: relatively naïve voters who accept money because they do not expect to be affected, and relatively sophisticated voters who accept money because the value of the gift exceeds the difference in their candidate preferences. Since a relatively naïve voter expects to not switch his vote, he will only make Promise 1 if the utility of keeping a promise exceeds the value of the gifts $\left(\gamma \geq g_{1}+\right.$ $\mathrm{g}_{2}$ ). If this condition holds it is sufficient for the voter to keep a promise he has made. Relatively sophisticated voters recognize they will change their vote after accepting the gift from Candidate 2, so their threshold for making the promise accounts for this $\left(\gamma \geq g_{1}+g_{2}-\right.$ $\left.\left(\mathrm{v}_{1}-\mathrm{v}_{2}\right)\right)$.

\footnotetext{
12 See the appendix for additional details.

${ }^{13}$ Note that since a partially sophisticated voter always underestimates the impact of a gift, he will always accept a gift from Candidate 2 that will in reality not affect his vote, i.e. (1) does not hold.
} 


\section{Promise 2}

At $\mathrm{t}=1$ a partially sophisticated voter who has promised to vote his conscience will anticipate that a gift from Candidate 2 will change his vote if

$$
\varphi^{\prime}\left(\mathrm{g}_{2}-\mathrm{g}_{1}\right)-\left(\mathrm{v}_{1}-\mathrm{v}_{2}\right)>2 \gamma
$$

Again, we focus on the case where the gift from Candidate 2 is large enough to change his vote if there is no promise (i.e. 1 holds and either 3 holds or $\mathrm{g}_{2}$ is large enough). As above we consider relatively naïve voters and relatively sophisticated voters. Relatively naïve voters expect to keep their promise, so they will make the promise and accept both gifts. For the promise to reduce vote selling compared to the base case we need we need the promise to prevent vote switching, i.e. (2) does not hold. Therefore we need the promise keeping utility to be sufficiently strong and/or the reciprocal preference to be in an intermediate range. Relatively sophisticated voters expect to change their votes even with the promise if they accept the gift from Candidate 2. Therefore to make the promise he must prefer to turn down the gift and vote for Candidate 1 than accepting both gifts and voting for Candidate 2. He will make the promise if $\gamma \geq g_{2}-\left(v_{1}-v_{2}\right)$.

So as in the previous case the promise to vote your conscience can be effective if the utility from keeping a promise is sufficiently strong.

\section{Harmful Promise to Vote Your Conscience}

Unlike the promise not to accept money, the promise to vote your conscience can actually have a negative effect and increase the amount of vote switching for partially sophisticated voters. This can happen if the voter is sophisticated enough to turn down the gift from Candidate 2 absent a promise, but naïve enough to mistakenly believe that the promise will prevent him from switching. Specifically, this outcome can happen if (3) holds and $g_{2}$ is not too large $\left(g_{2}<v_{1}-v_{2}\right)$, so without the promise the voter correctly recognizes that accepting the gift will change his vote, and he is willing to turn down the money. However, if (4) does not hold, then the voter thinks that after making the promise the gift will no longer affect his vote. We saw previously that in this case the voter will always accept the money, and also will always be willing to make the promise. If (2) does hold, then the voter is wrong - after accepting the money he will in fact change his vote. If these conditions hold then the promise actually increased the amount of vote switching the voter did not switch his vote in the base case, but does switch his vote when asked to 
make the promise. Furthermore, this negative effect for the promise to vote your conscience can occur simultaneously with more positive effects for other promises and races. $^{14}$

\section{Reported Voting}

So far we have considered how the promises affect actual voting behavior. However, in our experiment we only observe subjects' self-reports of their votes. One might imagine that subjects may distort their reported votes due to social desirability bias the reluctance in a survey to report behavior contrary to prevailing norms or expectations (Nederhof 1985, Fisher and Katz 2000, Holbrook and Krosnick 2010). We discuss here how such biases could change reported voting, and whether they could generate our anticipated results.

We anticipate that subjects' initial candidate ratings will be an accurate reflection of their underlying preferences. The candidate ratings occur before subjects know they will be asked to promise not to sell their vote. Hence voters cannot rate a candidate as their favorite in advance so that they can appear to keep their promises by appearing not to switch their votes.

If our model is correct and subjects report their voting truthfully, then the conditions described above should identify which voters will switch their vote. With truthful reporting this will coincide with the observed switching. How might social desirability bias change these reports? One natural form of social desirability bias would be for any voter to be reluctant to report switching their vote, due to the general norm against vote selling. ${ }^{15}$ A straightforward way of representing this would be to assume a voter who actually switched his vote will only report switching with probability $p<1$. In this case the observed switching rates would be biased towards zero. However, there will only be a difference in observed switching rates if there is a difference in true switching rates. Therefore this form of bias cannot create the treatment differences our model predicts.

\footnotetext{
${ }^{14}$ For example, consider two elections - one with low gift sizes and one with larger gifts. Suppose that $\left(\mathrm{v}_{1}, \mathrm{v}_{2}\right)=(10,1)$ for both races, $\left(\mathrm{g}_{1}, \mathrm{~g}_{2}\right)=(2,4)$ for the low gift race, $\left(\mathrm{g}_{1}, \mathrm{~g}_{2}\right)=(4,8)$ for the high gift race,$\varphi^{\prime}=$ 2.5, $\varphi=12$, and $\gamma=7$. Then it is straightforward to show that in the low stakes race the promise not to accept money decreases vote selling compared to the base case, while the promise to vote your conscience has no effect. Similarly, in the high stakes race the promise not to accept money has no effect, while the promise to vote your conscience increases vote selling.

${ }^{15}$ In the appendix we include a simple formalization of this intuition.
} 
An alternate possibility would be for the social desirability bias to focus on promise-breaking, rather than vote selling generally. Then only the switching rates for Promise 2 will be distorted, since the only voters switching in the Promise 1 treatment are those that did not make the promise. In this case, any observed treatment effect for Promise 1 cannot be generated by this bias. Additionally, the switching rates for Promise 2 are biased towards zero, so this cannot generate an increase in switching from Promise 2.

If instead the bias affects any voter asked to make a promise, then the observed switching rates in both promise treatments might be affected. However, comparisons between races can demonstrate that the promise must be having an effect. If the bias affects both races equally, then any difference between races in a promise treatment can only be generated by differences in true switching rates. If voters exhibit different biases depending on the race, we would generally expect larger biases in the more important races than in the less important races. ${ }^{16}$ In this case we would expect larger biases for the mayoral and vice-mayoral election compared to the city council election, and hence the apparent effect of the promise would be most beneficial in the higher stakes elections. In order to observe that the promise was more effective in the city council race, voters would have to feel more uncomfortable appearing to break their promise in the city council election than in the mayoral election, which seems unlikely. Furthermore, as before this kind of bias can only make the promises look beneficial, and would never make them look harmful.

\section{Predictions: Differentiating between theoretical cases}

Empirical evidence on the impact of Promises 1 and 2 on vote-switching behavior can distinguish among the model's theoretical cases. Our empirical analysis will estimate the impact of each promise on vote-switching in three different electoral races. Let $\beta_{i j}$ be the impact of promise $i \in[1,2]$ on vote-switching in electoral race $j \in[\mathrm{m}, \mathrm{v}, \mathrm{c}]$ (mayor, vice-mayor, and city council).

As discussed above, there is a potential that social desirability effects could bias the treatment effects $\beta_{i j}$ in the negative direction, raising concerns about spurious findings for

\footnotetext{
${ }^{16}$ This assumption is consistent with models of promises and experimental evidence on lying. For example, Gneezy and Erat (2011) find that lying rates for "white lies" depend on the payoff consequences of the lie. Similarly, Miettinen (2013) models the guilt from breaking a promise as increasing in the payoff consequence of the promise violation.
} 
individual $\beta_{i j}$ estimates. However, as discussed in the previous sub-section, as long as social desirability bias is similar across the promise treatments (which seems reasonable), conclusions related to the difference between impacts of Promises 1 and $2\left(\beta_{l j}-\beta_{2 j}\right)$ are robust to the presence of social desirability bias. We therefore highlight model predictions regarding the difference in impacts across promise treatments, $\beta_{l j}-\beta_{2 j}$.

Both the fully sophisticated and fully naïve cases make the predictions that 1) both promise treatments should reduce vote-switching $\left(\beta_{i j}<0, \forall i, j\right)$, and 2$)$ the impact of the Promise 2 treatment will be larger in magnitude $\left(\beta_{l j}-\beta_{2 j}>0, \forall j\right)$.

In the partially sophisticated case, on the other hand, the predictions are different. The Promise 1 treatment should reduce vote-switching $\left(\beta_{l j}<0, \forall j\right)$, but the impact of the Promise 2 treatment vote-switching can be either negative $\left(\beta_{2 j}<0, \forall j\right)$ or positive $\left(\beta_{2 j}>0\right.$, $\forall j$ ). The difference in the impact of Promise 1 from Promise $2, \beta_{l j}-\beta_{2 j}$, can therefore be positive or negative.

The following table summarizes the model's predictions in each case:

\begin{tabular}{c|c|c|c|}
\multicolumn{1}{c}{} & \multicolumn{1}{c}{$\begin{array}{c}\text { Partially } \\
\text { Sophisticated }\end{array}$} & \multicolumn{1}{c}{$\begin{array}{c}\text { Fully } \\
\text { Sophisticated }\end{array}$} & \multicolumn{1}{c}{ Fully Naive } \\
$\beta_{l j}$ & $<0$ & $<0$ & $<0$ \\
\cline { 2 - 4 }$\beta_{2 j}$ & $>0$ or $<0$ & $<0$ & $<0$ \\
\cline { 2 - 4 }$\beta_{l j}-\beta_{2 j}$ & $>0$ or $<0$ & $>0$ & $>0$ \\
\cline { 2 - 4 } & &
\end{tabular}

A finding that Promise 1 reduces vote-switching more than does Promise $2\left(\beta_{1 j}-\beta_{2 j}\right.$ $<0)$ can only be generated by the partially sophisticated case, not the fully sophisticated or fully naïve cases.

\section{Predictions: Differential effects across races}

The model also makes predictions regarding the relative effects of the promises across electoral races that involve different sizes of vote-buying payments (gifts). In our context, the mayor and vice-mayor races involve larger vote-buying payments, compared to the city council races.

For Promise 1, which can only reduce vote-switching, the model predicts that the treatment will have more negative effects for races that involve smaller vote-buying 
payments (in other words, the city council race, compared to either the mayor or vicemayor race): $\beta_{l c}-\beta_{l m}<0$ and $\beta_{l c}-\beta_{l v}<0$.

Promise 2 can either have a positive or negative effect on vote-switching, and there is no unambiguous prediction as to the relationship between the Promise 2 treatment effect magnitude and the size of vote-buying payments. The fully naïve, fully sophisticated and partially sophisticated cases are all potentially consistent with finding a more negative effect of Promise 2 in the city council election. However, if the Promise 2 treatment leads to an increase in vote-switching in races with larger vote-buying payments (the mayor and vice-mayor races) and either no effect or a decrease in vote-switching in the city council race, then this pattern is informative because it only occurs in the partial sophistication case of the model (not the fully sophisticated or fully naïve cases).

Again, these comparisons across races are robust to the presence of social desirability bias, if this bias is constant across races. If social desirability bias is different across races it is more likely that it would be larger (the bias would be more negative) in the more important races (mayor and vice-mayor), in which case social desirability bias makes it more difficult to reject the null in these tests for differential treatment effects across races. Finding that Promise 1 has a more negative effect in the city council race and/or that Promise 2 has a more positive effect in the mayor and vice mayor races is therefore evidence that our results are not entirely driven by social desirability bias.

\section{Experimental Design and Data Collection}

We implemented a randomized controlled trial of treatments encouraging individual voters not to sell their votes. Study participants were registered voters in Sorsogon City. Participants were selected from the Certified List of Voters that we obtained from the Commission on Elections (COMELEC). The list included the name, address, date of birth, gender, and the assigned polling precinct of each of Sorsogon City's 84,284 registered voters. ${ }^{17}$ From this list, we randomly selected 900 primary targeted respondents and 900 alternates.

\footnotetext{
${ }^{17}$ The registration deadline for the May 2013 elections was October 2012, so this list was the complete list of registered voters for our election of interest.
} 
Prior to fielding the baseline survey and intervention, primary respondents and alternates were randomly assigned to the control or treatment groups. One-third of individuals were randomly assigned to the control group, one-third to the Promise 1 treatment, and one-third to the Promise 2 treatment.

\section{Baseline Survey and Voter Educational Video}

The baseline survey and treatments were administered prior to the May 13, 2013 elections for Sorsogon City mayor, vice-mayor, and city council. A local team of enumerators administered the baseline survey, treatment interventions, and the endline survey. Surveys were administered on a hand-held device (an iPad) using an offline survey app (iSurvey). The baseline survey was fielded from April 17 to May 8, 2013 (5 to 26 days prior to the election).

Enumerators located primary respondents at their residential addresses, invited them to participate in the research study using a recruitment script (see Online Appendix B), and obtained consent to participate in the study. When a primary respondent could not be interviewed due to out-migration, refusal, or being deceased, the enumerator sought to interview an alternate respondent with the same treatment assignment. ${ }^{18}$ Following this procedure, we generated a sample of 883 respondents, just slightly below the target sample of $900 .^{19}$

The baseline survey was administered immediately before the experimental treatments, and asked questions about participants' demographics, past experience with vote-selling, expectations about monetary offers, and preference ratings for the candidates for mayor, vice-mayor, and city council. We also asked participants to rate each candidate for mayor, vice-mayor, and city council according to how favorable they felt towards each candidate on a 7-point Likert scale (-3=extremely unfavorable, $0=$ neutral, $3=$ extremely favorable).

After completing the baseline survey, all participants were shown a three-minute video clip on the hand-held device. The video clip was part of a humorous voter education

\footnotetext{
18 The list of alternates was sorted according to a randomly assigned number. When replacing primary respondents who could not be interviewed, enumerators picked alternates in the prescribed randomized order. ${ }^{19}$ In total, enumerators sought to locate 1,496 voters. Reasons for unsuccessful baseline surveys were as follows: failed to contact after repeated visits (170 voters), out of town (154), migrated out of Sorsogon City (92), refused (65), moved to unknown location (65), deceased (21), and other (27). This led to 902 voters being administered the baseline survey. Of these, 19 provided incomplete baseline responses, yielding our baseline sample of 883 .
} 
campaign encouraging viewers to turn out to vote, vote for honest and competent candidates, and avoid vote-selling. ${ }^{20}$ The video clip was shown to all respondents to ensure that those in control and treatment groups received similar appeals not to sell their votes. This is important because the promise treatments, by themselves, might be construed as including an implicit suggestion not to sell one's vote. Our interest is in evaluating the effectiveness of the promise treatments themselves, over and above appeals to eschew vote-selling. Making an explicit appeal to all respondents not to sell their votes (by showing the video) helps sharpen the interpretation of the treatments as being due to the promises elicited, and not due to any appeal not to sell one's vote that might be perceived as bundled with the promise elicitation.

\section{Treatments}

At the end of the voter educational video clip, respondents in the two treatment groups (Promise 1 and Promise 2) were invited to make promises not to sell their votes in the upcoming election, in ways that differed across the treatments. ${ }^{21}$ Individuals in the Promise 1 treatment were asked to make a promise not to accept money from any candidate, while those in the Promise 2 treatment were asked to promise to vote according to their conscience even if they accepted money.

Elicitation of the promises was implemented by showing respondents a screen on the hand-held device. For Promise 1, the screen is reproduced as Figure 1.a). The text on the screen reads "Would you promise not to take the money from any candidate or local leader before the elections?" For Promise 2, the screen image can be seen as Figure 1.b), and the corresponding text is "If any candidate or local leader gives you money before the elections and you decide to keep it, would you promise to vote according to your conscience?"

On both screens, participants were asked to tap on either of the images shown in the figures to register their response. Tapping the left image (of a handshake, above the words "Yes, I promise.") would signify agreement to promise, and tapping the right image

\footnotetext{
${ }^{20}$ The video clip features Mae Paner, a political activist and actress, as the fictional character "Juana Change." The video can be viewed here: http://www.youtube.com/watch?v=10Jh8Nzu7Zs

${ }^{21}$ The majority of vote-buying in Sorsogon happens in the few days in advance of the election, so the treatments were administered roughly two weeks prior to the period when vote-buying payments were made.
} 
(of an open hand in a "halt" signal, above the words "No, I can't make that promise.") would indicate refusal to promise.

A participant who agreed to make the promise by tapping on the image of the handshake was then asked, on the next screen, to write the words "I promise" on a blank space using their finger. ${ }^{22}$ After the signature, participants were asked two additional questions on politics and vote-buying, and the survey ended. ${ }^{23}$

\section{Post-Election Survey}

We fielded an endline survey of the same study participants from May 17 to June 8, 2013, a period spanning 4 to 26 days after the May 13, 2013 midterm election. The endline survey collected data on whether respondents voted (turn-out), as well as which candidates they voted for in each race (mayor, vice-mayor, and city council). We achieved a high (95.9\%) endline survey success rate, and this rate is not differential by treatment status (as discussed further below).

\section{Empirical Strategy}

\section{Proxy for vote-selling}

The Philippines has a secret ballot, so measurement of vote-selling behavior is a first-order challenge. We did not ask participants directly whether they sold their votes, due to concerns about experimenter demand or social desirability bias. If individuals in the treatment groups underreported the extent to which they sold their votes, this would lead to spurious findings that the treatments reduced vote-selling.

Our approach instead is to simply ask participants in the endline who they voted for in the individual races (for mayor, vice-mayor, and city council), and to compare their reported votes in the endline survey with the candidate favorability ratings they reported in the baseline survey. Our key outcome variable is vote switching: an indicator equal to one for a particular election race if the respondent reported in the endline survey that they voted for a candidate who they did not rank highest in the baseline survey for that position (in the Likert-scale elicitation), and zero if they did say in the endline that they voted for

\footnotetext{
${ }^{22}$ On that screen, the text read "Thank you for your promise. As a symbolic act of your solemn promise, please write the phrase 'I promise' on the space below."

${ }^{23}$ These last two questions were also asked of participants who refused to promise as well as of those in the control group (who were not asked to make any promises).
} 
their highest-rated candidate. We construct vote-switching indicators for each race separately, as well as indicators of whether the voter switched in any race. ${ }^{24}$

There are a number of reasons other than vote-selling why a voter may have voted for a candidate other than his or her top-rated candidate (e.g., learning new information.) We expect that such "legitimate" reasons should be unaffected by the promise interventions. Therefore, differences in vote-switching across treatment conditions should represent differences in vote-selling.

A few comments are in order regarding the use of vote switching as a proxy for vote-selling. First of all, it is important that candidate favorability ratings in the baseline must provide an unbiased indication of participants' true preferences for candidates. This is likely to be satisfied: our survey staff presented themselves as neutral and unaffiliated with any candidate or political party, and favorability ratings were elicited before respondents were exposed to any of our promise treatments.

In Section 3, we discussed empirical tests (comparisons of treatment effects across promises and across races) that are robust to the presence of social desirability bias. There also may be an a priori case to be made that social desirability bias may not be large to begin with. In the endline survey, we did not remind respondents that we had data on their candidate ratings from the baseline survey. It also requires a fair degree of sophistication for a respondent to recall that our project was about vote-selling, to recall their candidate preferences from the baseline, and to intentionally misreport their votes to be consistent with their original preferences. What's more, it should be far from clear to respondents that reporting in the endline that one voted for someone who was not their highest-rated choice in the baseline would be viewed by enumerators as ethically questionable, because voteswitching could occur for legitimate reasons (as mentioned above). Respondents, in essence, have "cover" to report at endline that they voted for someone other than their initially-preferred candidate, since such switches can occur for many reasons other than vote-selling.

If one believes that vote-switching is an acceptable proxy for vote-selling, and if our interventions are effective at reducing vote-selling, respondents in the treatment groups

\footnotetext{
${ }^{24}$ For the city council race, in which each voter casts votes for four candidates, vote switching is defined as voting for at least one candidate who was not among their top four rated candidates.
} 
should do less vote switching (as defined above). If, on the other hand, any of our treatments led to more vote-selling, we should see increases in the rate of vote switching.

\section{Regression specification}

We assess the effect of the promises on vote-switching by estimating the following ordinary-least-squares regression equation (a linear probability model):

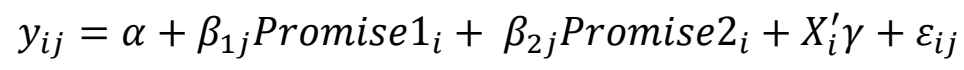

$y_{i j}$ is an indicator variable equal to 1 if the respondent switched his or her vote in race $j$, and 0 otherwise. Promise $1_{i}$ and Promise $2_{i}$ are indicator variables equal to 1 if the respondent was randomized into (respectively) the Promise 1 or Promise 2 treatment, and 0 otherwise. $\boldsymbol{X}_{\boldsymbol{i}}{ }_{i}$ is a vector of baseline (pre-treatment) control variables. $\varepsilon_{i j}$ is a mean-zero error term. We report robust (Huber/White) standard errors.

The coefficients of interest are $\beta_{1 j}$ and $\beta_{2 j}$ on the treatment indicators, which measure (respectively) the impact of treatment on the probability of vote-switching. To be clear, because making the promise is endogenous, we focus here on the effect of being in the promise treatment (being invited to make a promise), and not on whether the respondent actually made the promise. Our estimates are therefore intent-to-treat (ITT) effects.

As discussed in Section 3, we will also test model predictions that related to differences in treatment effects across races and promises.

\section{6. $\quad \underline{\text { Results }}$}

\section{Summary Statistics, Baseline Balance, and Promise Take-up}

Panel A of Table 1 reports summary statistics for key baseline variables, in the full sample (column 1) and in the subsamples by treatment condition (columns 2-4). The columns to the right report, for each baseline variable, the p-values of F-tests of the joint equality of means across treatment conditions as well as for pairwise combinations of the treatment conditions. There is no indication of substantial imbalance in baseline characteristics across treatment conditions. Out of 100 p-values shown in Panel A, 10 are below 0.10 , which is exactly the proportion that would be expected to occur by chance. To 
account for any biases generated by these chance imbalances, these baseline variables will be included as control variables in the regressions. ${ }^{25}$

Panel B of Table 1 reports similar summary statistics for promise-making and the key dependent variables of interest. The first row of this panel reports the fraction of respondents making the elicited promises in each treatment group. In each treatment group, slightly more than half of respondents make the promise - 51\% for Promise 1 ("Don't take the money") and 56\% for Promise 2 ("Take money, vote conscience") - and these proportions are not different from one another at conventional levels of statistical significance.

\section{Vote shares and candidate favorability ratings}

Table 2 provides relevant data for each candidate and electoral race. (Candidate names are omitted, and candidates are indicated by arbitrarily-assigned letters.) Candidates in bold are winners of their respective races, and starred candidates are incumbents. Reported vote shares in our sample (from the endline survey) correctly predict the actual winners in each race. The correlation coefficient between actual and sample-reported vote shares (columns 1 and 2) is 0.957.

Average favorability ratings across candidates from our endline survey are also highly correlated with vote shares. The correlation coefficient between the average favorability rating (column 3) and reported vote share in the sample (column 2) is 0.838 (and the corresponding correlation with the actual vote share in column 1 is 0.839 ). The remaining columns of the table display the distribution of discrete candidate favorability ratings, across the integers ranging from -3 to 3 . There is considerable variation in candidate favorability ratings across our survey respondents across the range of possible responses.

\section{Attrition from baseline to endline surveys}

To be included in the endline sample for analysis of a particular electoral outcome, a baseline respondent had to have: 1) completed the endline survey, 2) actually turned out to vote in the election, and 3) reported who they voted for in a given electoral race. If either treatment affected attrition (on any of these margins), one might worry that any observed

\footnotetext{
${ }^{25}$ Our results are robust to exclusion of the baseline control variables. Regression results and tests of theoretical predictions when control variables are not included in the regressions are presented in Appendix Tables 2 and 3, and should be compared with Tables 3 and 4 of the main text.
} 
treatment effects on vote-switching could be simply due to compositional changes in the sample. Out of the 883 baseline respondents, the share who completed the endline survey, voted, and reported their mayoral vote was $86.0 \%$. The corresponding shares for vicemayor and city council are $85.0 \%$ and $90.0 \%$.

Differences in these measures of attrition across treatment conditions are very small, and none are statistically significantly different from zero, so attrition bias is of little concern in this context. ${ }^{26}$ Please refer to Online Appendix $\mathrm{C}$ for further details.

\section{Impact of treatments on vote switching}

We first present our results in graphical form. Figure 2 displays the bar graphs of the fraction vote switching, by treatment condition, with $95 \%$ confidence intervals. Figure 2(a) presents the share of respondents who switched votes in at least one of the races. In the control group, $57.4 \%$ of subjects switched their vote at least once, compared to $50.4 \%$ in the Promise 1 treatment, and $61.8 \%$ in the Promise 2 treatment. This provides a first indication that the promise treatments had opposite effects, with asking subjects not take money from candidates reducing the amount of vote switching, while asking subjects to vote their conscience even if they take money increases the amount of vote switching.

Figures 2(b) and 2(c) examine vote switching separately in, respectively, the mayor/vice-mayor races and the city council race. In the mayor/vice-mayor races, vote switching rates are very similar in the control and Promise 1 groups $(26.4 \%$ and $27.1 \%$, respectively), but higher in the Promise 2 group (33.7\%). By contrast, for the city council race, the control and Promise 2 groups have similar vote switching rates $(47.1 \%$ and $47.7 \%$, respectively), while the rate for the Promise 1 group is much lower, at $38.4 \%$.

To confirm these visual impressions, we now turn to estimation of regression equation (1) for vote switching in different races. Results are presented in Table 3.

In column 1, the dependent variable is vote switching in any race. As in Figure 2(a), the coefficient for the Promise 1 treatment is negative, while the coefficient for Promise 2 is positive. The negative coefficient on Promise 1 is statistically significantly different from zero at the $5 \%$ level.

\footnotetext{
${ }^{26}$ In results available upon request, we also find that, among respondents completing the endline survey, there is no effect of either promise treatment on turning out to vote.
} 
In columns 2-4 we examine treatment effects in specific races (mayor, vice-mayor, and city council, respectively). These results reveal that the estimated effect on overall vote switching estimated in column 1 obscures heterogeneity of treatment effects across races.

In regressions for vote-switching in the mayor or vice-mayor races, the coefficient on Promise 1 is always relatively small in magnitude and negative in sign. The coefficient on Promise 2, on the other hand, is larger in magnitude, and positive in sign in both cases. None of these promise treatment effects for the mayor or vice-mayor races are statistically significantly different from zero at conventional levels.

The pattern is quite different in analysis of vote switching in the city council race (column 4). The Promise 1 treatment has a large, negative and statistically significant (at the $5 \%$ level) effect on vote switching, amounting to a 10.9 percentage point reduction. The corresponding coefficient for Promise 2 is also negative but, by contrast, is very small in magnitude and is not statistically significantly different from zero.

\section{Estimating the amount of social desirability bias}

Examination of individual treatment coefficients may be misleading, because social desirability bias may lead estimated promise treatment effects to be biased in a negative direction (i.e., for treatments to appear to reduce vote switching). As discussed in Section 3 , however, we present tests of differences in treatment effects across promises and across races that are robust to the presence of social desirability bias.

In addition, examining the impact of the Promise 1 treatment in the more important races can provide an indication of the likely magnitude of social desirability bias. If social desirability bias is constant across electoral races (e.g., a constant multiplicative factor $p$ applied to vote-switching rates in all races, as discussed in Section 3), and if true Promise 1 treatment effects are zero for the higher-money races (mayor and vice-mayor), then the Promise 1 treatment effect in the higher-money races provides an estimate of the magnitude of social desirability bias. If the Promise 1 treatment does have some true effect on reducing vote-switching in the higher-money races, then this estimate will be an upper bound of the true magnitude of social desirability bias. Also, if social desirability bias is not constant across electoral races but is larger in the more important races (mayor and vice-mayor), this estimate will also be an upper bound. 
The pattern of Promise 1 treatment effects across races reported in Table 3 indeed suggests that social desirability bias is not a significant concern in this setting. Promise 1 treatment effects in the mayor and vice-mayor races, while both negative, are quite close to zero, and neither are statistically significantly different from zero. The coefficient in the mayor's race is worth particular attention, since the mayor's race is the most important race of the three. The coefficient (-0.003) indicates a reduction in vote-switching of threetenths of a percentage point, which is very small relative to the control group mayoral election vote-switching rate of 10.6 percent. Assuming no "true" Promise 1 treatment effect on vote-selling in the mayor's race, taking this coefficient seriously would imply $p=$ 0.97 (social desirability bias leads the self-reported vote-switching rate to be $97 \%$ of the true vote-switching rate). Given this, we conclude that our estimated treatment effects (the $\beta_{i j}$ estimates) are likely to be minimally affected by reporting bias. ${ }^{27}$

\section{Tests of theoretical predictions}

We turn our attention to tests of theoretical predictions. These involve pairwise comparisons of treatment coefficients across promises and races, and are summarized at the end of Section 3.

\section{Effects more negative for Promise 1 than Promise 2 treatment}

Part A of the table tests predictions of the partially sophisticated theoretical case, which unlike the other cases (fully sophisticated and fully naïve), is the only case that predicts a particular pattern found in Table 3's regression results: that Promise 1 has a more negative impact on vote-switching (reduces vote-switching more) than does Promise 2. We first conduct this test across treatment effects in the vote-switching regression pooled across races (coefficients in column 1 of Table 3). The difference in coefficients is negative and statistically significant at the 5\% level.

When conducting this test separately for each race, we find that for each race Promise 1 has a more negative impact than Promise 2: $\beta_{l j}-\beta_{2 j}<0$ in each race $j$. For the city council race, the difference is statistically significantly different from zero at the $5 \%$ level.

\footnotetext{
${ }^{27}$ An analogous assessment of the magnitude of social desirability bias is not possible for the Promise 2 treatment, because it is theoretically possible for that treatment to have a true positive effect on voteswitching, alongside any negative reporting bias due to social desirability effects.
} 
To test whether the theoretical prediction that Promise 1's impact is more negative than Promise 2's holds across all races considered simultaneously, we conduct an F-test of the joint hypothesis that $\beta_{l m}-\beta_{2 m}=0$ and $\beta_{l v}-\beta_{2 v}=0$ and $\beta_{l c}-\beta_{2 c}=0$. We reject this hypothesis at the $1 \%$ level (the p-value, reported in the bottom row of Part A of Table 4, is 0.005). This result provides statistical confirmation that the full set of empirical results is consistent with the partially sophisticated case, and not the fully sophisticated or fully naïve cases of the model.

Effects more negative for city council than in either mayor or vice-mayor races

The theoretical model predicts that the impact of the Promise 1 treatment on voteswitching will be more negative for the race with the lower vote-buying payments (the city council race) than for those with higher vote-buying payments (the mayor and vice-mayor races). The prediction regarding differentials in Promise 2's effects across races is ambiguous; Promise 2's effect could be either higher or lower in the city council race compared to the other races.

We conduct pairwise tests of the differential effects of the treatments across electoral races in Part B of Table 4. The results reveal that, within each promise treatment, pairwise differences in treatment effects between the city council regression, on the one hand, and either the mayor or vice-mayor regression, on the other, are all negative in sign. These differences are statistically significant at the $10 \%$ level or better for the Promise 1 comparisons. While the Promise 2 cross-race tests are not statistically significantly different from zero, the negative point estimates for the differences and the positive point estimates on the Promise 2 treatment coefficient (Table 3, columns 2 and 3) can only occur in the partial sophistication case of the model (not the fully sophisticated or fully naïve cases.)

As an overall test whether the prediction that each promise treatment is more negative for the city council race than in the other races, we conduct an F-test of the joint hypothesis that $\beta_{1 c}-\beta_{l m}=0$ and $\beta_{1 c}-\beta_{1 v}=0$ and $\beta_{2 c}-\beta_{2 m}=0$ and $\beta_{2 c}-\beta_{2 v}=0$. This hypothesis is rejected at the $10 \%$ level (the p-value, reported in the bottom row of Part B of Table 4 , is 0.086).

$\underline{\text { Test of joint significance all pairwise treatment effect differences }}$ 
Finally, we conduct an F-test of the joint significance of all the pairwise tests examined in Parts A and B. We reject at the 1\% level the hypothesis that the pairwise treatment effect differences examined in Parts A and B are jointly zero (the p-value is 0.008 , reported in Part C of Table 4).

\section{Conclusion}

We propose a behavioral model of transactional electoral politics in which selling one's vote is a temptation good, generating utility for the future self upon the vote-sale, but not for the present self who anticipates later selling his or her vote. We also allow keeping or breaking promises to have utility consequences, so voters can use promises related to vote-selling as a commitment device. In the model, a promise not to take money from candidates can reduce vote-selling, but a different type of promise (to take vote-buying payments, but to nonetheless vote according to one's underlying candidate preferences) can have a smaller effect, and even possibly increase vote-selling, if voters are partially naïve about (underestimate) their vote-selling temptation.

We present empirical evidence from a randomized controlled trial of an anti-voteselling intervention in the Philippines that is consistent with the model's predictions. The pattern of results supports a particular case of the theoretical model, wherein voters are only partially aware of their vote-selling temptation. The results rule out full sophistication as well as full naïveté about one's vote-selling temptation.

From a policy standpoint, our results reveal that exceedingly simple interventions such as eliciting promises not to sell votes - can help reduce vote-selling. We estimate that a promise not to take money from candidates leads to a reduction in vote-switching (our proxy for vote-selling) of 10.9 percentage points (compared to a rate of 47.1 percent in the control group) in the electoral race that involved the smallest vote-buying payments (the city council race). Patterns in the results for other races indicate that this treatment effect estimate is likely to be minimally biased by social desirability effects. We find no evidence that promises help reduce vote-selling in the races (for mayor and vice-mayor) in which vote-buying payments are larger.

These results reveal that approaches from behavioral economics or psychology can help us understand important phenomena in political economy, such as vote-selling 
transactions. Future research would do well to incorporate the behavioral factors we have highlighted into theoretical and empirical analyses of transactional electoral politics, and of vote-selling in particular.

\section{$\underline{\text { References }}$}

Acemoglu, Daron, James A. Robinson, and Rafael J. Santos. (2009) “The Monopoly of

Violence: Evidence from Colombia.” National Bureau of Economic Research Working Paper No. 15578.

Baland, J-M. and J.A. Robinson. (2008) "Land and Power: Theory and Evidence from

Chile.” American Economic Review. 98(5): 1737-65.

Banerjee, Abhijit and Sendhil Mullainathan (2010), "The Shape of Temptation:

Implications for the Economic Lives of the Poor," working paper.

Blaydes, L. (2006) "Who votes in authoritarian elections and why? Determinants of voter turnout in contemporary Egypt.” APSA 2006 Annual Meeting paper.

Bratton, Michael. (2008) "Vote Buying and Violence in Nigerian Election Campaigns."

Electoral Studies. 27(4): 621-632.

Callahan, William A. (2000) Pollwatching, Elections and Civil Society in Southeast Asia. Aldershot, Hampshire: Ashgate.

Charness, Gary and Martin Dufwenberg. (2006). "Promises and Partnership." Econometrica. 74(6): 1579-1601.

Chen, Y., N. Kartik and J. Sobel. 2008. "Selecting Cheap-Talk Equilibria." Econometrica, 76(1): 117-136.

Desposato, Scott W. (2007) "How does vote buying shape the legislative arena?" Schaffer F.C., ed., Elections for Sale: The Causes and Consequences of Vote Buying. Boulder, CO: Lynne Rienner. pp. 144-79.

Duflo, Esther, Michael Kremer, and Jonathan Robinson (2011), "Nudging Farmers to Use Fertilizer: Theory and Experimental Evidence from Kenya," American Economic Review, Vol. 101, No. 6, 2350-90.

Ellingsen, T. and M. Johannesson. 2004. "Promises, Threats and Fairness." Economic Journal, 114(495): 397-420.

Erat, S. and U. Gneezy (2011) "White Lies." Management Science, 58 (4), 723-733. 
Finan, Frederico and Laura Schechter. (2012) "Vote-Buying and Reciprocity." Econometrica. 80(2): 863-881.

Fisher, Robert J. and James E. Katz. (2000). "Social-desirability bias and the validity of self-reported values," Psychology \& Marketing, 17: 105-120.

Fox, Jonathan. (1994) “The difficult transition from clientelism to citizenship: Lessons from Mexico.” World Politics. 46(1): 151-84.

Fudenberg, Drew and David K. Levine (2006). “A Dual Self Model of Impulse Control," American Economic Review, 96 (5): 1449-1476.

Geronimo, Gian (2013) “Concerned groups launch anti-vote-buying campaign,” GMA News online, February 13. http://www.gmanetwork.com/news/story/294800/news/nation/concerned-groupslaunch-anti-vote-buying-campaign

Golden, M. and D. Tiwari. (2009) “Criminality and Malfeasance among National Legislators in Contemporary India.” APSA 2009 Annual Meeting paper.

Graziano, Luigi. (1973) "Patron-client relationships in Southern Italy.” European Journal of Political Research. 1(1): 3-34.

Guiang, Alfred (2013), “Anti-vote-buying mass held at Q.C. church to promote electoral honesty and integrity," Philippine Information Agency, March 18. http://ncr.pia.gov.ph/index.php?article=281363581025

Gul, Faruk and Wolfgang Pesendorfer (2001), "Temptation and Self-Control," Econometrica, Vol. 69, No. 6, 1403-1435.

Hicken, Allen. (2011) “Clientelism.” Annual Review of Political Science. 14(1): 289-310.

Hicken, Allen and J.W. Simmons. (2008) "The personal vote and the efficacy of education spending.” American Journal of Political Science. 52(1): 109-24.

Holbrook, Allyson L., and Jon A. Krosnick. (2010). "Social desirability bias in voter turnout reports: Tests using the item count technique," Public Opinion Quarterly. 74(1): 37-67.

Keefer, Philip. (2006) "Programmatic parties: Where do they come from and do they matter?" Presented at the Annual Meeting of the American Political Science Association, Aug. 31-Sep. 3, Philadelpia. 
Keefer, Philip. (2007) "Clientelism, credibility, and the policy choices of young democracies.” American Journal of Political Science. 51(4): 804-21.

Kessler, Judd and Stephen Leider. (2012) "Norms and Contracting." Management Science. 58(1): 62-77.

Khemani, Stuti, "Buying Votes versus Supplying Public Services: Political Incentives to Under-invest in Pro-poor Policies,” working paper, World Bank, 2013.

Kitschelt, Herbert. (2007) "The demise of clientelism in affluent capitalist democracies."

Kitschelt H, Wilkinson SI, eds. Patrons, Clients, and Policies: Patterns of Democratic Accountability and Political Competition. Cambridge, UK: Cambridge Univ. Press. pp. 298-321.

Kitschelt, Herbert, Kirk A. Hawkins, Juan Pablo Luna, Guillermo Rosas, and Elizabeth J. Zechmeister. (2010) Latin American Party Systems. Cambridge, UK: Cambridge Univ. Press.

Kitschelt Herbert and Steven I. Wilkinson. (2007) "A research agenda for the study of citizen-politician linkages and democratic accountability.” Kitschelt H, Wilkinson SI, eds. Patrons, Clients, and Policies: Patterns of Democratic Accountability and Political Competition. Cambridge, UK: Cambridge Univ. Press. pp. 322-43

Kaur, Supreet, Michael Kremer, and Sendhil Mullainathan (2013), "Self-control at Work," working paper, Harvard University.

Krupka, Erin, Stephen Leider and Ming Jiang. (2013). "A Meeting of the Minds: Informal Agreements and Social Norms.” Working paper.

Laibson, David (1997). “Golden Eggs and Hyperbolic Discounting,” Quarterly Journal of Economics, 112 (2): 443-477.

Lyne, Mona. (2007) "Rethinking economics and institutions: the voter's dilemma and democratic accountability." Kitschelt H, Wilkinson SI, eds. Patrons, Clients, and Policies: Patterns of Democratic Accountability and Political Competition.

Cambridge, UK: Cambridge Univ. Press. pp. 206-26.

Miettinen, Topi. (2013). "Promises and conventions: an approach to pre-play agreements," working paper.

Nederhof, Anton J. (1985) "Methods of coping with social desirability bias: a review," European Journal of Social Psychology, 15: 263-280. 
Ozer, O., Y. Zheng and K. Chen. 2011. "Trust in Forecast Information Sharing.” Management Science, 57(6):1111-1137.

Schaffer, Frederic Charles. (2005) "Clean Elections and the Great Unwashed: Educating Voters in the Philippines." Occasional Paper 21, School of Social Science, Institute for Advanced Study.

Scott, James C. (1969) "Corruption, Machine Politics, and Political Change." The American Political Science Review, 63(4): 1142-1158.

Shu, Lisa, Nina Mazar, Francesca Gino, Dan Ariely, and Max Bazerman, "Signing at the beginning makes ethics salient and decreases dishonest self-reports in comparison to signing at the end," Proceedings of the National Academy of Sciences, Vol. 109, No. 38, September 18, 2012, pp. 15197-15200.

Stokes, Susan C. (2005) "Perverse accountability: A formal model of machine politics with evidence from Argentina." American Political Science Review, 99(3): 315-325.

Stokes, Susan C., Thad Dunning, Marcelo Nazareno, and Valeria Brusco. (2013) Brokers, Voters, and Clientelism: The Puzzle of Distributive Politics. Cambridge, UK: Cambridge Univ. Press.

Vanberg, Christoph. (2008). "Why do people keep their promises? An experimental test of two explanations." Econometrica. 76(6): 1467-1480.

Vicente, Pedro C. (forthcoming) "Is Vote Buying Effective? Evidence from a Field Experiment in West Africa." Economic Journal. 


\section{Appendix: Model Details}

\section{Partially Sophisticated Voters}

Promise 1

Case 1: Relatively Nä̈ve Voter - (3) does not hold

At $\mathrm{t}=0$, if he makes and fulfills the promise the voter will get $\mathrm{U}=\mathrm{v}_{1}+\gamma$. If he doesn't he expects to accept both gifts and vote for Candidate $1\left(\mathrm{U}=\mathrm{v}_{1}+\mathrm{g}_{1}+\mathrm{g}_{2}\right)$. He will make the promise if $\gamma \geq g_{1}+g_{2}$. This is then sufficient to turn down the gifts at $t=1$.

Case 2: Relatively Sophisticated Voter - (3) holds and $g_{2}>v_{1}-v_{2}$

At $\mathrm{t}=1$, if the voter has made the promise he can accept neither gift $\left(\mathrm{U}=\mathrm{v}_{1}+\gamma\right)$, only the gift from Candidate $1\left(\mathrm{U}=\mathrm{v}_{1}+\mathrm{g}_{1}-\gamma\right)$, or both gifts $\left(\mathrm{U}=\mathrm{v}_{2}+\mathrm{g}_{1}+\mathrm{g}_{2}-\gamma\right)$.

Accepting both gifts dominates accepting only one gift because $g_{2}>v_{1}-v_{2}$. Therefore, the voter will keep his promise not to accept money from candidates if $\gamma \geq 1 / 2\left[g_{1}+g_{2}-\left(v_{1}-\right.\right.$ $\left.\mathrm{v}_{2}\right)$ ]. A voter will never make a promise he expects to break, so assume the condition holds. At $\mathrm{t}=0$, the voter can promise $\left(\mathrm{U}=\mathrm{v}_{1}+\gamma\right)$, or not promise $\left(\mathrm{U}=\mathrm{v}_{2}+\mathrm{g}_{1}+\mathrm{g}_{2}\right)$. He will promise if $\gamma \geq\left[g_{1}+g_{2}-\left(v_{1}-v_{2}\right)\right]$.

Promise 2

\section{Case 1: Relatively Nä̈ve Voter - (4) does not hold}

Since the voter does not expect gifts to change his vote, he will accept any gift offered at $\mathrm{t}=1$ (with or without the promise). Since he expects to accept both gifts and keep his promise, at $\mathrm{t}=0$ he will make the promise. For the promise to reduce switching we need the promise to be effective if made, i.e. (2) does not hold, and for the voter to switch without the promise, i.e. (1) holds and either (3) doesn't hold or $g_{2}>v_{1}-v_{2}$.

Case 2: Relatively Sophisticated Voter - (4) holds

At $\mathrm{t}=1$ he expects the gift from Candidate 2 to change his vote, so he can accept it and vote for $2\left(U=v_{2}+g_{1}+g_{2}-\gamma\right)$ or turn it down and vote for $1\left(U=v_{1}+g_{1}+\gamma\right)$. For the promise to prevent vote switching we need $\gamma \geq 1 / 2\left[g_{2}-\left(v_{1}-v_{2}\right)\right]$. Then at $t=0$, he can promise and get $\mathrm{U}=\mathrm{v}_{1}+\mathrm{g}_{1}+\gamma$ or not promise and get $\mathrm{U}=\mathrm{v}_{2}+\mathrm{g}_{1}+\mathrm{g}_{2}$. He will promise if $\gamma \geq g_{2}-\left(v_{1}-v_{2}\right)$.

\section{Reported Voting Model}


For a given candidate and race, let $S_{0}, S_{1}$ and $S_{2}$ denote the number of voters switching in the Control group, the Promise 1 treatment and the Promise 2 treatment respectively. With truthful reporting this will coincide with the observed switching. For the Control group, $\mathrm{S}_{0}$ will consist of two groups of voters ${ }^{28}$ : Group 1 voters who accept the gift from Candidate 2 expecting to switch (equations 1 and 3 hold and $g_{2}>v_{1}-v_{2}$ ) and Group 2 voters who accept the gift from Candidate 2 expecting not to switch (equation 1 holds and 3 does not hold). For the Promise 1 treatment, $S_{1}$ will consist of subsets Groups 1 and 2. Specifically, $S_{1}$ will consist of those in Group 1 who do not make the promise $(\gamma$ $<\mathrm{g} 1+\mathrm{g} 2-(\mathrm{v} 1-\mathrm{v} 2))$ and those Group 2 who do not make the promise $(\gamma<\mathrm{g} 1+\mathrm{g} 2)$. Therefore, we expect that $\mathrm{S}_{1} \leq \mathrm{S}_{0}$, and that the difference is smaller for races with large monetary gifts. $\mathrm{S}_{2}$ will also consist of subsets Groups 1 and 2. Specifically, there will be two separate subsets of Group 1: relatively sophisticated voters who do not want to make the promise (equation 4 holds but $\gamma<\mathrm{g} 2-(\mathrm{v} 1-\mathrm{v} 2)$ ) and relatively naïve voters who switch after making the promise (equation 4 does not hold but equation 2 does).

Additionally, from Group 2 there will be those that switch after making the promise (equation 2 holds). Lastly, there will be additional voters not part of $\mathrm{S}_{0}$ who now accept the gift from Candidate 2 expecting not to switch but who are wrong (equations 2 and 3 hold, equation 4 does not hold, and $\left.\mathrm{g}_{2}<\mathrm{v}_{1}-\mathrm{v}_{2}\right)$. $\mathrm{S}_{2}$ can therefore be either larger or smaller than $\mathrm{S}_{0}$.

To model social desirability bias suppose that any voter who actually switched his vote will only report switching with probability $\mathrm{p}<1$. In this case the observed switching rates would be biased towards zero: $\mathrm{pS}_{0}, \mathrm{pS}_{1}$ and $\mathrm{pS}_{2}$. However, there will only be a difference in observed switching rates if there is a difference in true switching rates: $p\left(S_{i}-\right.$ $\left.S_{j}\right)>0$ only if $\left(S_{i}-S_{j}\right)>0$. Therefore this form of bias cannot create the treatment differences our model predicts.

If social desirability bias only affects promise-breaking, rather than vote selling generally then the observed switching rates will be $\mathrm{S}_{0}, \mathrm{~S}_{1}$ and $\mathrm{pS}_{2}$, since only voters in Promise 2 would both promise and switch. If instead the bias affects any voter asked to

\footnotetext{
${ }^{28}$ All races and treatments may also include voters who have sincerely changed their preferences between the initial survey and the election, e.g. from learning more about the candidates or seeing a compelling campaign ad. This kind of preference change should not interact with any of the promise treatments, so the differences between treatments will not be driven by this group.
} 
make a promise comparisons between races can demonstrate that the promise must be having an effect. If the bias affects both races equally, then any difference between races in a promise treatment can only be generated by differences in true switching rates: $p\left(S_{i}-\right.$ $\left.\mathrm{S}_{\mathrm{i}}\right)>0$ only if $\left(\mathrm{S}_{\mathrm{i}}-\mathrm{S}_{\mathrm{i}}\right)>0$. If voters exhibit different biases depending on the race, we would generally expect voters to distort more in the more important races than in the less important races: $\mathrm{p}_{\mathrm{M}}<\mathrm{p}_{\mathrm{VM}}<\mathrm{p}_{\mathrm{CC}}$. This would lead to a larger apparent treatment effect in the mayoral race than the city council race, and would never lead to an apparent increase in switching. 


\section{Figure 1: Promise Treatments as Viewed by Participants}

a) Promise 1

PROMISE INTERVENTION 1: Would you promise to not take the money from any candidate or local leader before the elections?

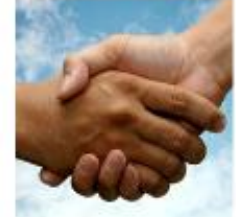

Yes, 1 promise.

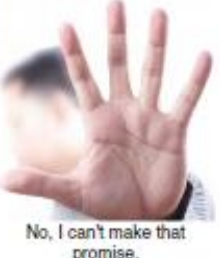

promise.

b) $\underline{\text { Promise } 2}$

PROMISE INTERVENTION 2: If any candidate or local leader gives you money before the elections and you decide to keep it, would you promise to vote according to your conscience?

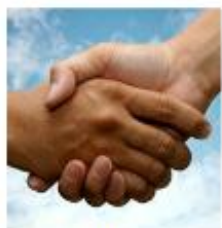

Yes, 1 promise.

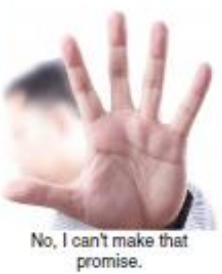

c) Signature

Thank you for your promise. As a symbolic act of this solemn promise, please write the phrase "I promise" on the space below.

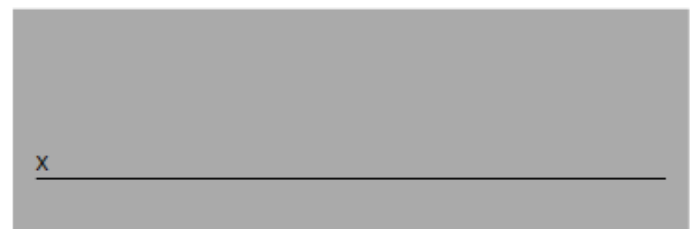




\section{Figure 2: Vote-Switching by Treatment Condition}

Figures show fraction of respondents switching their vote (voting for a candidate other than their top-rated candidate as reported in baseline survey), by treatment condition, along with $95 \%$ confidence intervals. Figure 2(a) shows fraction vote switching in any of the three races. Figure 2(b) shows fraction vote switching in either of the mayor or vice-mayor races. Figure 2(c) shows fraction vote switching in the city council race. (In city council race, voters can vote for up to four candidates. Vote switching in this race is defined as voting for at least one city council candidate who was not among the respondent's top four rated candidates in baseline survey.)

\section{a) Any Race}

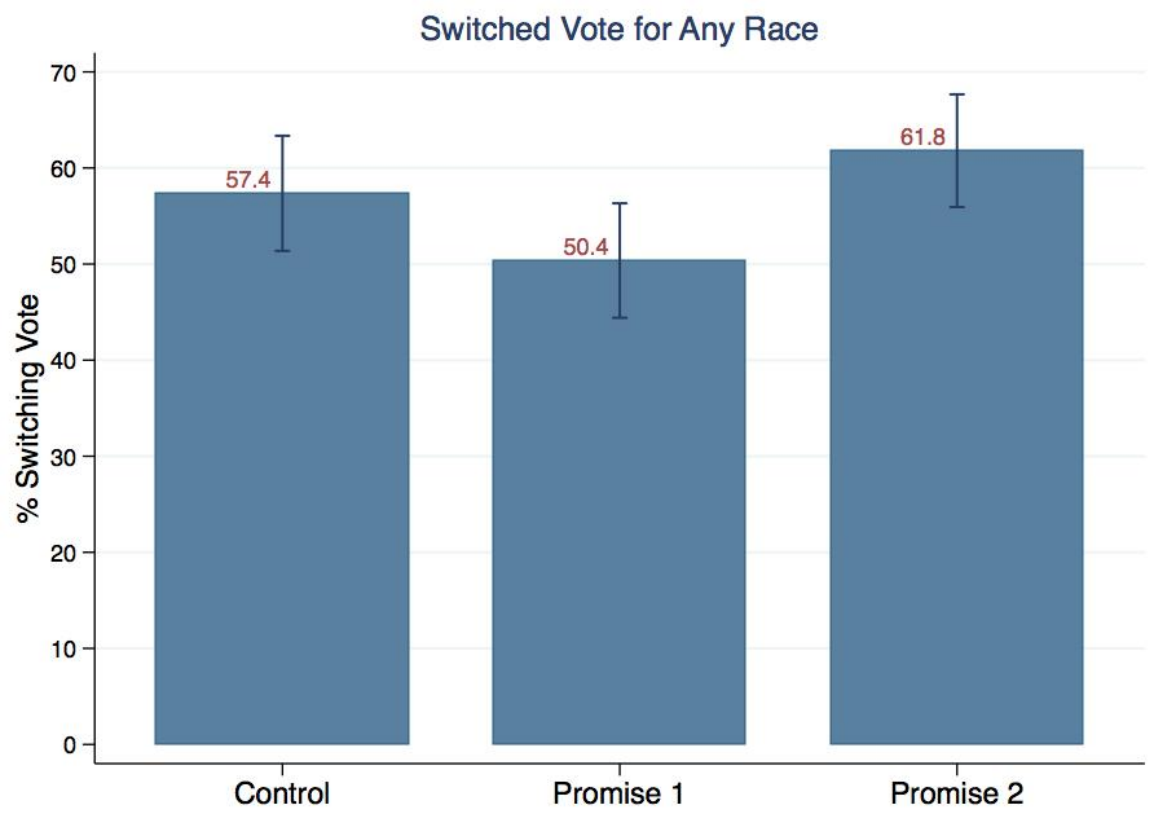


Figure 2 (continued)

b) Mayor or Vice-Mayor

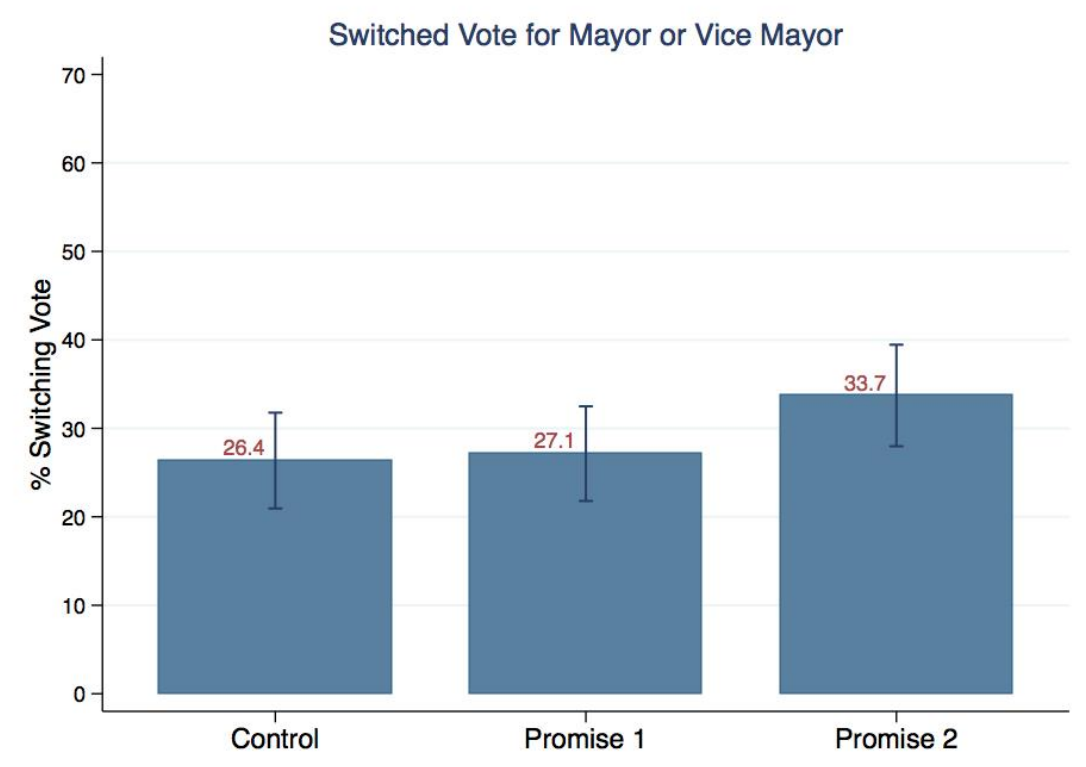

c) City Council

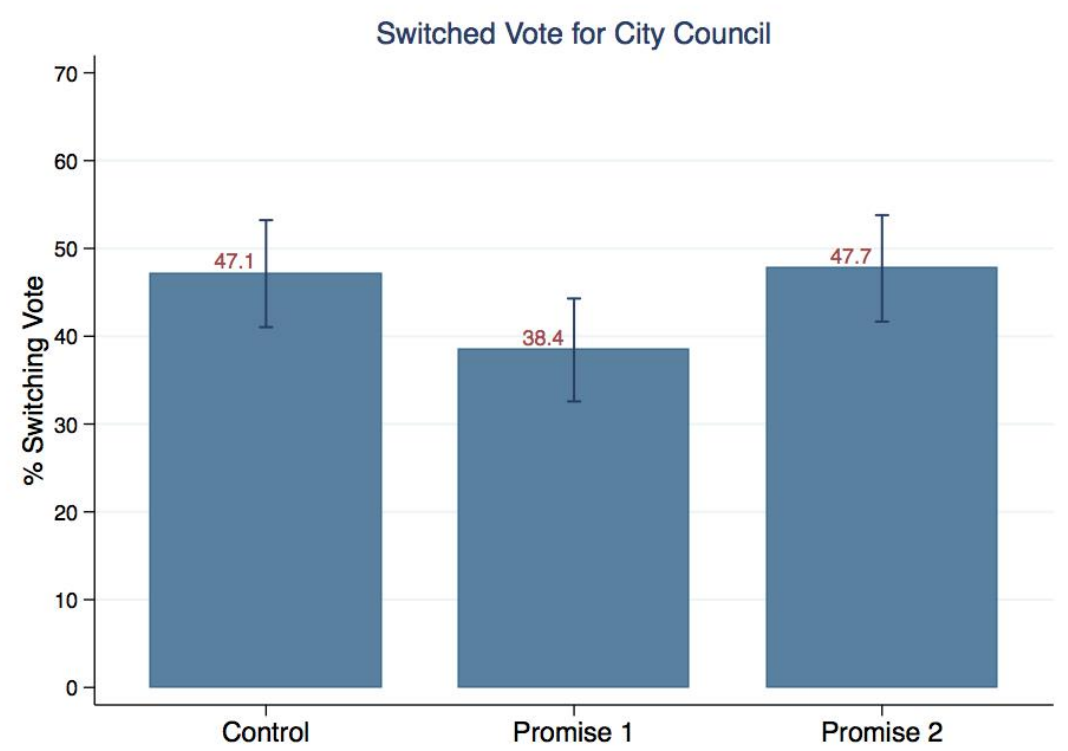


Table 1: Baseline Survey Summary Statistics and Balance Tests

Means (standard deviations)
Treatment groups $\quad P$-values

Promise $1 \quad \underline{\text { Promise } 2}$

("Don't take $\quad \frac{\text { ("Take money, }}{\text { vote }} C=P 1=\quad C=P 1 \quad C=P 2 \quad P 1=P 2$ money") $\underline{\underline{\text { conscience") }}}$

Number of observations 883

291

298

294

Panel A: Baseline Variables

Male (indicator)

Years of age

Religion is Catholic (indicator)

Number of voting household members

Marital Status (indicators)

Single

Married

Widowed

Domestic Partnership

Separated

Employment Status (indicators)

Choose not to work

Retired

Student

Unemployed and looking for job

Working full time

Working part time

Education (indicators)

Some Elementary to No Schooling

Elementary

Some Highschool

Highschool

Some College

College Up

Vocational

Migrant status (indicators)

Born here

Migrated as a child

Migrated as an adult

Panel B: Promise-Making and Outcome Variables

Made promise (indicator)

Switched Vote in Any Race (indicator)

Switched Vote for Mayor (indicator)

Switched Vote for Vice-Mayor (indicator)

Switched Vote for City Council (indicator)

$\begin{array}{ll}0.450 & 0.471 \\ 42.02 & 43.56 \\ (16.29) & (17.15) \\ 0.922 & 0.911 \\ 3.55 & 3.62 \\ (1.93) & (2.14)\end{array}$

$\begin{array}{ll}0.258 & 0.251 \\ 0.526 & 0.526 \\ 0.075 & 0.083 \\ 0.123 & 0.117 \\ 0.018 & 0.024\end{array}$

\subsection{9}

0.046

0.045

0.099

0.324

0.247

$\begin{array}{ll}0.120 & 0.127 \\ 0.176 & 0.151 \\ 0.193 & 0.210 \\ 0.168 & 0.165 \\ 0.131 & 0.131 \\ 0.039 & 0.028 \\ 0.174 & 0.189\end{array}$

$\begin{array}{ll}0.727 & 0.715 \\ 0.107 & 0.107\end{array}$

0.167

0.426
41.61
$(16.35)$
0.926
3.62

(1.81)

0.269
0.517
0.071
0.138
0.007

0.227

0.065

0.048

0.089

0.357

0.213

0.127

0.151

0.210

0.131

0.028

0.189

0.565

0.123

0.220

0.444

0.206

0.452
40.90
$(15.25)$
0.929
3.42
$(1.84)$

0.550

0.132

0.697

0.319

0.159

0.656

0.049

0.521

0.587

0.929

(1.84)

0.255
0.534
0.071
0.116
0.024

0.879

$0.916 \quad 0.827$

$0.836 \quad 0.584$

$0.673 \quad 0.451$

$0.094 \quad 0.088$

0.426

0.218

0.911

0.177

0.285
0.030
0.044
0.107
0.269
0.265

0.114

0.201

0.198

0.161

0.111

0.044

0.171

\subsection{5}

0.104

0.151

\subsection{4 \\ 0.135}

0.962

0.763

0.035

0.246

0.888

0.279

0.448

0.869

0.314

0.708

0.438

0.163

\subsection{1}

0.109

0.170

0.514

0.504

0.115

0.198

0.384

0.557

0.618

0.146

0.256

0.477

$\begin{array}{llll}0.682 & 0.410 & 0.866 & 0.512 \\ 0.982 & 0.921 & 0.928 & 0.850 \\ 0.646 & 0.366 & 0.784 & 0.528\end{array}$

Notes: Variables in Panel A collected in baseline survey, administered from April 17 to May 8, 2013 (prior to May 13, 2013 municipal elections). Promises (first variable in Panel B) were elicited at end of baseline survey. Remaining variables in Panel B are dependent variables in the analysis, and were constructed on the basis of reported voting in endline survey (May 17 to June 8, 2013). Respondents randomized with equal (1/3) probability into the control group, Promise 1 treatment group, or Promise 2 treatment group. P-values are for F-tests that mean of variable is equal across the specified treatment conditions. 
Table 2: Vote shares and candidate favorability ratings, by electoral race

May 13, 2013 municipal elections, Sorsogon City, Philippines

$\%$ of surveyed respondents rating candidate as...

\begin{tabular}{|c|c|c|c|c|c|c|c|c|c|c|}
\hline \multirow[b]{2}{*}{ Candidate } & \multirow[b]{2}{*}{$\frac{\frac{\text { Actual vote }}{\text { share in }}}{\underline{\text { election }}}$} & \multirow[b]{2}{*}{$\frac{\underline{\text { Reported }}}{\frac{\text { vote share }}{\text { (endline }}}$} & \multirow[b]{2}{*}{$\frac{\frac{\underline{\text { Sample }}}{\text { average }}}{\text { favorability }}$} & \\
\hline & & & & $\begin{array}{c}\text { Extremely } \\
\text { Unfavorable } \\
(-3)\end{array}$ & $\begin{array}{c}\text { Quite } \\
\text { Unfavorable } \\
(-2)\end{array}$ & $\begin{array}{c}\text { Slightly } \\
\text { Unfavorable } \\
(-1)\end{array}$ & $\begin{array}{l}\text { Neutral } \\
(0)\end{array}$ & $\begin{array}{l}\text { Slightly } \\
\text { Favorable } \\
\text { (1) }\end{array}$ & $\begin{array}{c}\text { Quite } \\
\text { Favorable } \\
\text { (2) }\end{array}$ & $\begin{array}{c}\text { Extremely } \\
\text { Favorable } \\
\text { (3) }\end{array}$ \\
\hline \multicolumn{11}{|l|}{ Mayor race } \\
\hline$A^{*}$ & 46.3 & 44.8 & 0.5 & 5.9 & 10.7 & 7.4 & 29.2 & 13.9 & 21.3 & 11.7 \\
\hline B & 48.0 & 55.2 & 0.6 & 3.2 & 8.0 & 6.5 & 30.7 & 21.7 & 21.1 & 8.8 \\
\hline \multicolumn{11}{|c|}{ Vice-mayor race } \\
\hline $\mathrm{C}$ & 30.0 & 30.2 & 0.3 & 2.5 & 17.0 & 7.8 & 27.5 & 19.6 & 20.3 & 5.3 \\
\hline $\mathrm{D}$ & 24.6 & 23.4 & 0.0 & 3.7 & 19.8 & 8.7 & 33.6 & 16.1 & 13.6 & 4.4 \\
\hline $\mathbf{E}$ & 32.9 & 46.5 & 0.4 & 3.1 & 13.7 & 6.3 & 29.8 & 18.2 & 21.9 & 7.0 \\
\hline \multicolumn{11}{|c|}{ City council race, Bacon District } \\
\hline $\mathrm{F}$ & 30.4 & 31.0 & 0.1 & 2.1 & 21.6 & 7.0 & 29.6 & 18.5 & 17.8 & 3.5 \\
\hline G & 24.5 & 24.5 & -0.2 & 4.9 & 25.1 & 7.0 & 33.1 & 12.5 & 13.9 & 3.5 \\
\hline $\mathbf{H}^{*}$ & 37.8 & 46.0 & 1.0 & 1.1 & 8.4 & 2.4 & 24.0 & 19.5 & 35.5 & 9.1 \\
\hline I & 10.2 & 11.1 & -0.3 & 3.8 & 27.9 & 8.0 & 35.2 & 8.7 & 14.3 & 2.1 \\
\hline $\mathbf{J}$ & 32.7 & 44.4 & 0.6 & 1.1 & 13.2 & 5.9 & 30.7 & 15.3 & 25.1 & 8.7 \\
\hline $\mathbf{K}$ & 32.5 & 39.9 & 0.4 & 2.4 & 15.7 & 4.9 & 27.5 & 19.9 & 22.0 & 7.7 \\
\hline $\mathbf{L}^{*}$ & 37.3 & 54.0 & 0.7 & 1.7 & 13.2 & 7.0 & 21.6 & 16.4 & 32.1 & 8.0 \\
\hline $\mathrm{M}$ & 15.8 & 17.6 & -0.1 & 2.8 & 23.3 & 8.4 & 32.4 & 15.0 & 16.0 & 2.1 \\
\hline $\mathrm{N}$ & 17.1 & 18.8 & 0.0 & 2.8 & 23.3 & 5.6 & 30.7 & 15.3 & 17.4 & 4.9 \\
\hline $\mathrm{O} *$ & 25.5 & 24.9 & 0.2 & 2.4 & 21.3 & 5.2 & 30.3 & 15.3 & 16.7 & 8.7 \\
\hline $\mathrm{P}$ & 20.1 & 14.6 & -0.2 & 4.2 & 26.8 & 6.6 & 32.4 & 12.2 & 14.6 & 3.1 \\
\hline \multicolumn{11}{|c|}{ City council race, East District } \\
\hline $\mathrm{Q}^{*}$ & 31.3 & 28.7 & 0.3 & 1.8 & 18.7 & 7.8 & 26.5 & 15.9 & 26.5 & 2.8 \\
\hline $\mathrm{R}^{*}$ & 20.4 & 23.0 & 0.6 & 1.1 & 13.8 & 6.0 & 24.0 & 21.2 & 28.3 & 5.7 \\
\hline S & 6.6 & 4.6 & -0.6 & 4.6 & 33.9 & 8.5 & 35.0 & 10.3 & 7.1 & 0.7 \\
\hline $\mathrm{T}^{*}$ & 29.7 & 33.0 & 0.8 & 0.4 & 12.0 & 3.2 & 23.0 & 23.3 & 31.1 & 7.1 \\
\hline $\mathrm{U}$ & 3.2 & 1.5 & -0.8 & 2.8 & 36.8 & 11.0 & 35.7 & 10.6 & 3.2 & 0.0 \\
\hline $\mathrm{V}$ & 5.5 & 1.2 & -0.6 & 2.1 & 32.5 & 11.3 & 39.9 & 10.3 & 3.5 & 0.4 \\
\hline $\mathbf{W}$ & 40.5 & 60.2 & 0.6 & 0.4 & 13.1 & 4.6 & 25.8 & 21.2 & 30.0 & 5.0 \\
\hline $\mathbf{X}$ & 45.4 & 60.2 & 0.8 & 0.7 & 12.0 & 6.4 & 24.4 & 14.8 & 28.6 & 13.1 \\
\hline $\mathbf{Y}$ & 44.4 & 54.0 & 0.3 & 0.4 & 20.1 & 6.4 & 29.3 & 15.9 & 23.7 & 4.2 \\
\hline $\mathbf{Z}$ & 34.5 & 39.5 & 0.1 & 1.4 & 21.6 & 9.9 & 27.9 & 19.1 & 16.3 & 3.9 \\
\hline AA & 15.1 & 13.8 & 0.0 & 0.7 & 20.9 & 7.8 & 35.7 & 17.7 & 14.8 & 2.5 \\
\hline$A B$ & 9.2 & 4.2 & -0.5 & 2.5 & 31.1 & 9.5 & 35.7 & 12.4 & 8.5 & 0.4 \\
\hline AC & 18.2 & 11.9 & 0.5 & 1.4 & 17.7 & 2.8 & 24.7 & 22.3 & 25.4 & 5.7 \\
\hline \multicolumn{11}{|c|}{ City council race, West District } \\
\hline $\mathrm{AD}$ & 5.0 & 4.2 & -0.1 & 2.6 & 19.8 & 11.2 & 37.7 & 11.8 & 14.7 & 2.2 \\
\hline $\mathrm{AE}$ & 20.1 & 13.4 & 0.2 & 2.9 & 14.4 & 7.4 & 35.5 & 19.8 & 18.5 & 1.6 \\
\hline AF* & 49.8 & 60.8 & 1.1 & 0.0 & 8.0 & 1.9 & 26.8 & 14.7 & 36.4 & 12.1 \\
\hline AG & 32.7 & 43.8 & 0.4 & 0.3 & 13.4 & 7.7 & 34.8 & 16.9 & 24.0 & 2.9 \\
\hline $\mathrm{AH}$ & 18.2 & 19.1 & 0.3 & 1.6 & 17.3 & 5.4 & 38.3 & 11.8 & 17.3 & 8.3 \\
\hline AI & 37.3 & 50.9 & 0.9 & 1.9 & 10.9 & 2.9 & 23.6 & 12.8 & 36.4 & 11.5 \\
\hline AJ* & 38.4 & 59.0 & 0.7 & 1.3 & 10.2 & 4.8 & 29.1 & 19.2 & 29.7 & 5.8 \\
\hline $\mathrm{AK}$ & 27.4 & 23.7 & 0.5 & 1.0 & 12.1 & 5.1 & 34.2 & 17.3 & 21.1 & 9.3 \\
\hline AL* & 34.6 & 50.9 & 0.7 & 1.0 & 9.6 & 4.5 & 29.4 & 18.2 & 31.6 & 5.8 \\
\hline $\mathrm{AM}$ & 3.1 & 4.2 & -0.5 & 1.9 & 28.1 & 11.2 & 43.5 & 9.0 & 5.8 & 0.6 \\
\hline AN & 9.7 & 7.4 & -0.3 & 1.9 & 23.6 & 9.6 & 43.1 & 13.1 & 7.4 & 1.3 \\
\hline $\mathrm{AO}$ & 8.3 & 4.6 & -0.3 & 2.9 & 24.3 & 8.3 & 45.7 & 7.0 & 9.6 & 2.2 \\
\hline
\end{tabular}

Notes: Data on actual vote share in election are from Philippine Commission on Elections (COMELEC). Reported vote share is from our endline survey. Favorability ratings are from our baseline survey. Starred $\left(^{*}\right)$ candidates are incumbents (but not all incumbents ran again in this election). Bold candidates are winners of their respective races. In city council races, top four candidates are elected. 
Table 3: Impact of Treatments on Vote-Switching

Ordinary least-squares regressions

\section{Dependent variable:}

Promise 1 treatment
("Don't take money")
Promise 2 treatment
("Take money, vote conscience")

Control variables

Observations

R-squared

\section{Switched Vote in Any Race}

(1)

$$
\begin{array}{cc}
\beta_{1} & -0.0953^{* *} \\
& (0.0429) \\
\beta_{2} & 0.0309 \\
& (0.0427)
\end{array}
$$

\section{$\mathrm{Y}$}

806

0.046
Switched Vote

for Mayor

(2)

$$
\begin{array}{cc}
\beta_{1 m} & -0.00329 \\
& (0.0278) \\
\beta_{2 m} & 0.0288 \\
& (0.0299)
\end{array}
$$

Y

759

0.037

Switched Vote

for Vice-Mayor

(3)

$$
\begin{array}{lc}
\beta_{1 v} & -0.0221 \\
& (0.0365) \\
\beta_{2 v} & 0.0391 \\
& (0.0383)
\end{array}
$$

Y

751

0.041
Switched Vote

for City Council

(4)

$-0.109 * *$

(0.0430)

$\beta_{2 c} \quad-0.00945$

(0.0439)

Y

\begin{tabular}{|c|c|c|c|c|c|c|c|}
\hline \multicolumn{2}{|c|}{ Races pooled } & \multicolumn{2}{|c|}{ Mayor race } & \multicolumn{2}{|c|}{ Vice-mayor race } & \multicolumn{2}{|c|}{ City council race } \\
\hline$\beta_{1}-\beta_{2}$ & $\begin{array}{c}-0.126^{* *} \\
(0.043)\end{array}$ & $\beta_{1 m}-\beta_{2 m}$ & $\begin{array}{l}-0.032 \\
(0.030)\end{array}$ & $\beta_{1 v}-\beta_{2 v}$ & $\begin{array}{l}-0.061 \\
(0.037)\end{array}$ & $\beta_{1 c}-\beta_{2 c}$ & $\begin{array}{c}-0.100^{* *} \\
(0.043)\end{array}$ \\
\hline
\end{tabular}

793

0.042

${ }^{* * *} \mathrm{p}<0.01,{ }^{* *} \mathrm{p}<0.05,{ }^{*} \mathrm{p}<0.1$

Notes: Robust (Huber/White) standard errors in parentheses. Dependent variable in columns 1-10 equal to 1 if respondent switched his/her vote in the given race or set of races, 0 otherwise. Vote switching in mayor and vice-mayor races defined as voting for a candidate not receiving respondent's highest favorability rating in baseline (pre-election) survey. Vote switching in city council race defined as voting for a candidate not among the respondent's topfour highest-favored candidates in baseline survey. Respondents randomized with equal (1/3) probability into the control group, Promise 1 treatment group, or Promise 2 treatment group. Control variables are listed in Panel A of Table 1 and were reported in baseline survey prior to treatment.

\section{Table 4: Tests of Theoretical Predictions}

\section{A. Testing predictions of partially sophisticated theoretical case (within race, effects more negative for Promise 1 than Promise 2)}

\section{B. Testing prediction of differential effects across races (within promise, effects more negative for city council than in either mayor or vice-mayor races)}

Comparing across races, for Promise 1:

Comparing across races, for Promise 2:

$$
\begin{array}{cccc}
\beta_{1 c}-\beta_{1 m} & -0.106^{* *} & \beta_{1 c}-\beta_{1 v} & -0.087^{*} \\
& (0.049) & & (0.053) \\
\beta_{2 c}-\beta_{2 m} & -0.038 & \beta_{2 c}-\beta_{2 v} & -0.049
\end{array}
$$

\section{All theoretical predictions in A. and B. combined}

$$
\begin{aligned}
& \text { P-value of F-test: }\left(\beta_{1 m}-\beta_{2 m}=0\right) \&\left(\beta_{1 m}-\beta_{2 m}=0\right) \&\left(\beta_{1 m}-\beta_{2 m}=0\right) \\
& \&\left(\beta_{1 c}-\beta_{1 m}=0\right) \&\left(\beta_{1 c}-\beta_{1 v}=0\right) \&\left(\beta_{2 c}-\beta_{2 m}=0\right) \&\left(\beta_{2 c}-\beta_{2 v}=0\right)
\end{aligned}
$$

*** $\mathrm{p}<0.01,{ }^{* *} \mathrm{p}<0.05,{ }^{*} \mathrm{p}<0.1$

Notes: Table reports tests of linear combinations of coefficients suggested by theory. Robust (Huber/White) standard errors in parentheses. $\beta_{i j}$ is impact of promise $i$ on vote-switching in race $j$ in regressions reported in Table 3. 


\title{
Online Appendix for
}

\section{Temptation in Vote-Selling: Evidence from a Field Experiment in the Philippines}

\author{
Allen Hicken \\ Department of Political Science, U. Michigan \\ Stephen Leider \\ Stephen M. Ross School of Business, U. Michigan \\ Nico Ravanilla \\ Department of Political Science and Gerald R. Ford School of \\ Public Policy, U. Michigan \\ Dean Yang \\ Department of Economics and Gerald R. Ford School of Public \\ Policy, U. Michigan; BREAD; and NBER
}

\section{Appendix A: Vote buying in Sorsogon}

While the experiment was in the field, two of the authors were on the ground in Sorsogon observing election campaigning, interviewing local candidates and campaign workers, and on occasion, accompanying candidates and campaign workers as they worked to buy votes. Almost all candidates and workers were very open about the fact that their campaigns engaged in vote buying. ${ }^{1}$ Many expressed regret that they were forced to do so, but in the words of one candidate, "We have no choice. Voters expect it."

While the particulars differ from candidate to candidate, the following is typical of what we heard from candidates and their campaign workers.

\section{Pre-campaign preparation: Patronage and Organization Building}

The groundwork for an election campaign is laid long before formal campaigning begins. Those intending to run for office work assiduously to cultivate relationships with voters in the years and months prior to election day by providing services to constituents. These can include everything from providing free food (one candidate regularly provides a free breakfast for anyone who shows up at his door), help with medical bills or school fees, to "KBL"- - attending and giving financial support at weddings (kasal), baptisms (binyag), and burials (libing). Obviously, the expectations of such goods and services are higher from a politician currently in office than from a challenger, but even challengers need to engage in these types of patronage efforts if they hope to be a viable candidate.

Candidates also begin very early building an effective campaign organization. The goal is to have campaign leaders who are loyal to the candidate in every barangay (roughly, a village; the smallest official administrative unit in the Philippines). Interestingly, even where there are party or clan ties among candidates for different offices, candidates tend not to share campaign organizations or workers. "You have to have your own leaders who work just for you" one village councilor candidate reported. Well before the campaign period begins these local canvassers develop lists of voters by household and categorize them as supporters of the candidate, supporters of an opponent, and "loose" or uncommitted voters. ${ }^{2}$

\footnotetext{
${ }^{1}$ However, since such activities violate election law, we will not identify individuals by name.

${ }^{2}$ We were able to view one such voter list from a candidate running for councilor.
} 
Early campaign period: Rallies, Visits and Handouts

As the official campaign period begins, candidates spend time attending official campaign events, sometimes on their own, sometimes with candidates for other offices. Typical at these events are free food and entertainment for participants, as well as other (generally non-monetary) handouts, including t-shirts, foodstuffs (rice, noodles, coffee), etc. Candidates also spend time meeting with voters in less formal settings, including visiting local markets, and being present at events where large numbers of voters are likely to be gathered. Most candidates reported that they spent little time talking to voters about policy issues. Small sectors of the community might care about such issues, "but for a majority, all they care about is personal help.” Accordingly candidates must typically also deal with a deluge of requests for assistance during the campaign period. While there is some variation, at this stage of the campaign candidates are not doing much to distinguish between likely supporters and non-supporters. All who come to the rallies receive handouts, and candidates respond positively to all those petitioners that they can. To do otherwise would risk the candidate's reputation.

\section{Late campaign period: Vote buying}

Things change dramatically in the week before election day. It is during this period that vote buying occurs. Using the voter lists each campaign has developed, vote canvassers approach households directly, offering money or goods in exchange for the vote. This is a massive logistical enterprise, involving the movement of large amounts of cash and goods, and the coordination of a large network of vote canvassers. Two campaigns we visited had their vote canvassers visiting the campaign head-quarters throughout the day, three days before the election, to pick up their allotment of money and pre-packaged noodles (Appendix Figure 1). We accompanied another campaign during a midnight run to distribute money and noodles to canvassers a few days prior to the election.

Candidates report that vote buying is generally done systematically and strategically. The more experienced local leaders with established networks in their barangay or purok (roughly translated as district or neighborhood) typically ask household heads to come to a designated place (usually the local leader's house) at a designated time (typically at night) to pick up the packets to be given to the voting members of the household. "Inpatawag ka ni kap," ("Our barangay captain is asking for you,") is understood to mean the packets are ready to be claimed. This is most efficient, since money stays in one secure place, there are fewer intermediaries required to conduct the vote-buying, and household heads can be made to sign a document that they, in fact, received the money.

Not all households and voters are brazen enough to make the trip to a local leader's camp to pick up money. To reach out to these voters, local canvassers make house-to-house visits, sometimes in broad daylight, to hand out packets to individual voters or to household heads. "Pwede tabi maghatag?” (“Can I give you something?”) or "May iharatag tabi ako saindo." ("I have something to give you,") are some of the phrases vote canvassers use when handing out the packets. Voters may then accept or refuse these packets. These packets would typically contain the name of the voter and the 
voter's assigned precinct number, so the campaign can track who accepted and who did not (Appendix Figure 2).

Campaigns do not attempt to buy the votes of all voters. The top priority is individuals identified as likely supporters, followed by those who are viewed as unaffiliated or uncommitted. Few vote buying resources are wasted on those already believed to be supporters of another candidate. While unaffiliated voters may receive offers of money from multiple rival candidates, most voters receive offers from only a single candidate. Candidates may also engage in a second round of vote buying if they learn that a challenger is offering more money than they are.

Campaigns are very careful to be sure voters clearly associate the money or gift with the correct candidate. For example, the candidate's flyer may be stapled to packages of instant noodles handed out to voters (Appendix Figure 3), or cash may be attached to the flyer or letter from the candidate (Appendix Figure 4). The most common strategy, however, is for candidates to distribute money attached to a sample ballot. They encourage voters to take the ballots with them to the polls as a guide. The sample ballot includes not just the candidate's name, but also candidates from other races up and down the ticket. Appendix Figure 5 contains four examples of vote buying using sample ballots. $^{3}$

\section{Monitoring local leaders' efforts and voter behavior}

Philippine polls have used automated ballot readers since 2010, making monitoring how voters actually vote challenging for candidates. ${ }^{4}$ It is possible for candidates to connive with election officers who administer polling places. Election officers can, in limited circumstances, find excuses to help voters insert their ballots into ballot readers and observe contents of the ballot. However, such situations are rare and are kept in check by independent election monitors. In the vast majority of cases voters are likely to be able to keep their ballots secret.

Candidates use election results as an imprecise mechanism to audit the performance of local leaders who are buying votes for them. For example, candidates providing funds to a barangay meant to buy 500 votes would expect to receive at least 500 votes from that barangay. This, of course, is a very crude method, and cannot be used to check whether any individual sold his or her vote.

\footnotetext{
${ }^{3}$ One candidate went to great lengths to explain why the bottom left ballot was superior to the bottom right ballot (Figure 5). Both candidates were offering the same amount (300 pesos) but the candidate on the bottom right made the rookie mistake of not "fanning" the money so that all of the bills were immediately visible, and then compounded this mistake by stapling the money to back of the ballot rather than front. ${ }^{4}$ Before automated polling, indirect methods for confirming vote-buying transactions included what were known as "clave" ("key") methods, in which voters would signal in some way on the ballot itself that they had sold their vote. For example, when voting, voters who received vote-buying payments would agree to vote for only the single candidate who had bought the vote (and not other candidates on the ballot for other elected positions). The manual process of tabulating votes involved reading out in public the votes on every single paper ballot, and so the number of ballots with votes for just a single candidate could be tallied by election observers allied with the vote-buying candidate. A variation on the "clave" method involved having vote-sellers write in the name of someone not running for another elected position (e.g., the name of a popular media personality). The number of write-in votes for the media personality would be counted to track the number of votes sold.
} 


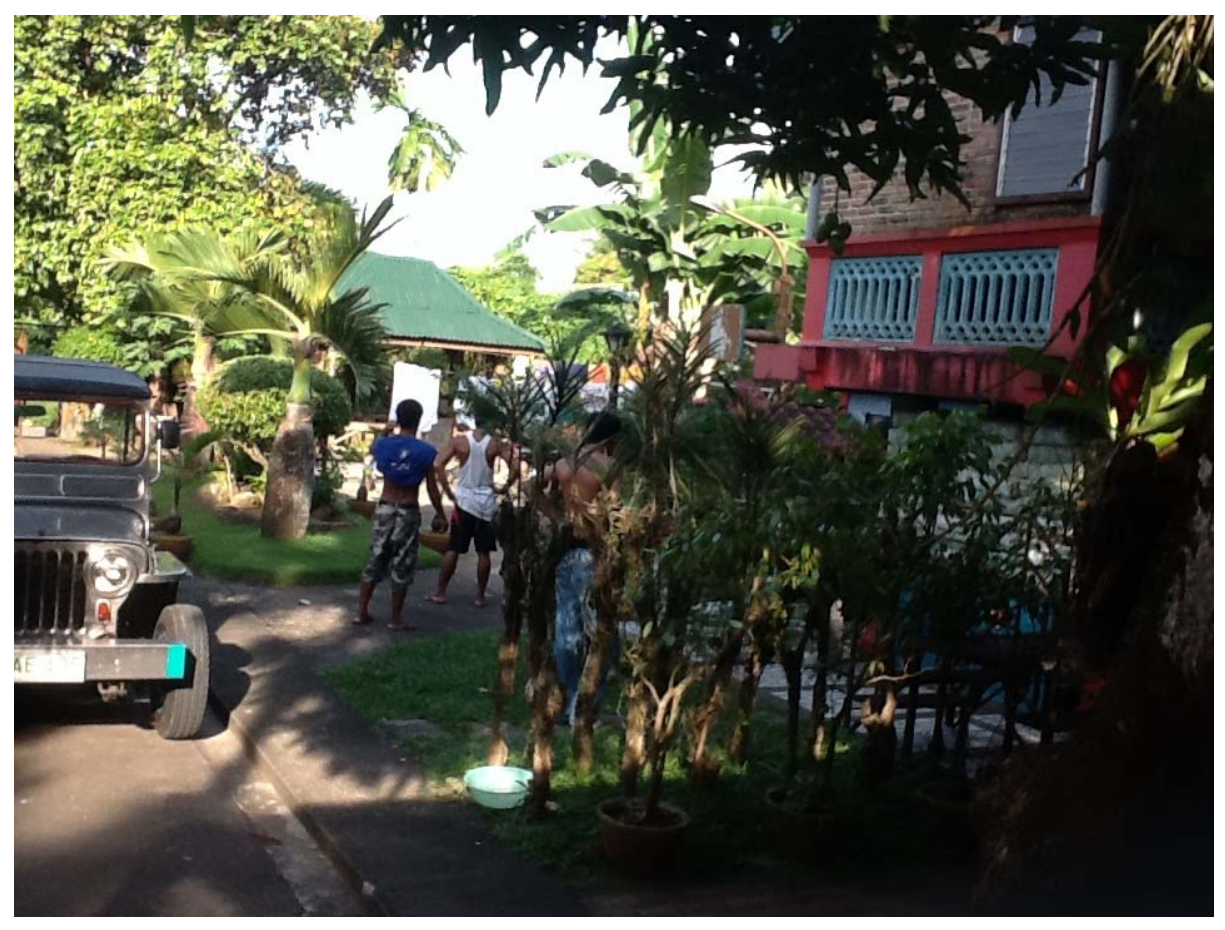

Appendix Figure 1: Cases of instant noodles awaiting distribution under the red house, and campaign workers waiting to pass those noodles out to vote canvassers as they arrive.

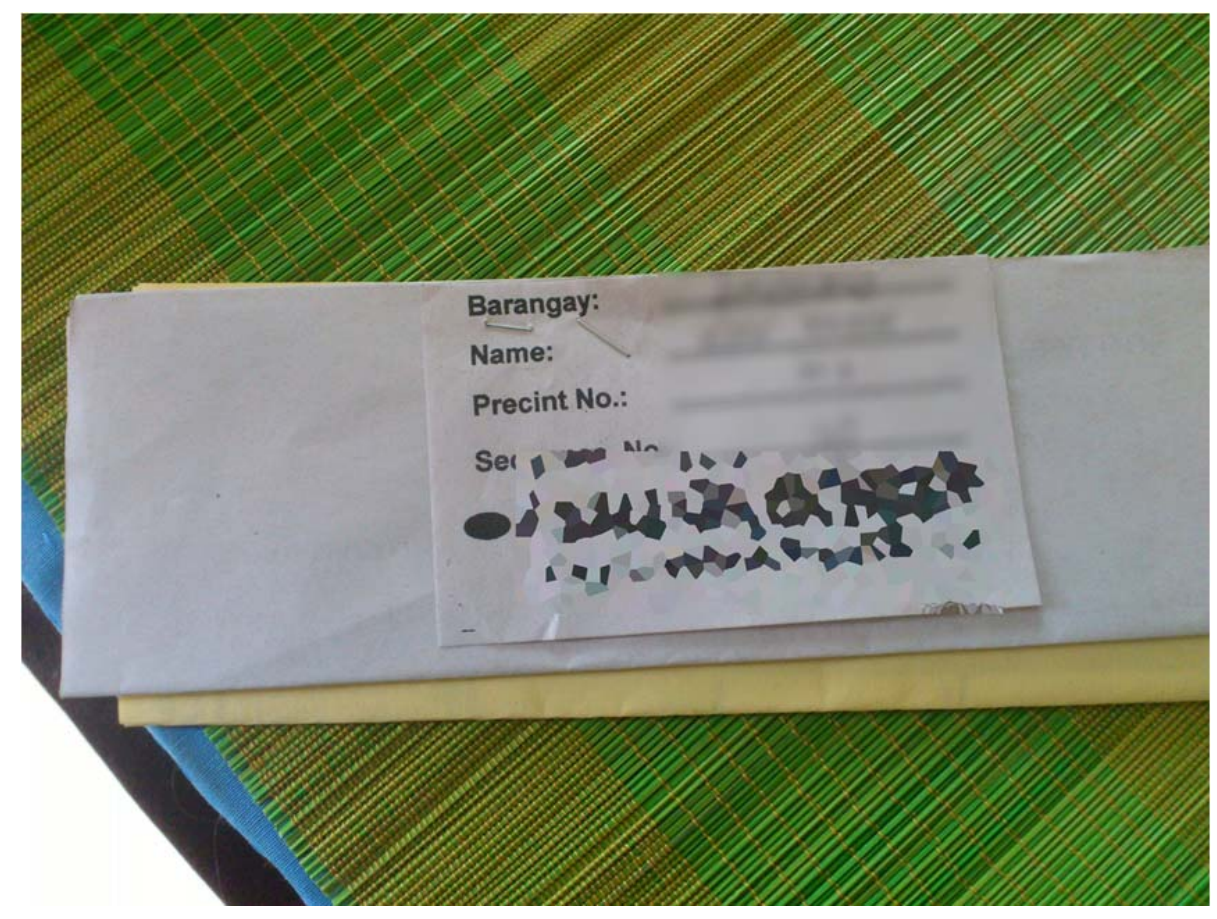

Appendix Figure 2: Vote buying packet distributed to voter with voter name and information written in, and candidate name printed in large bold letters at the bottom. 


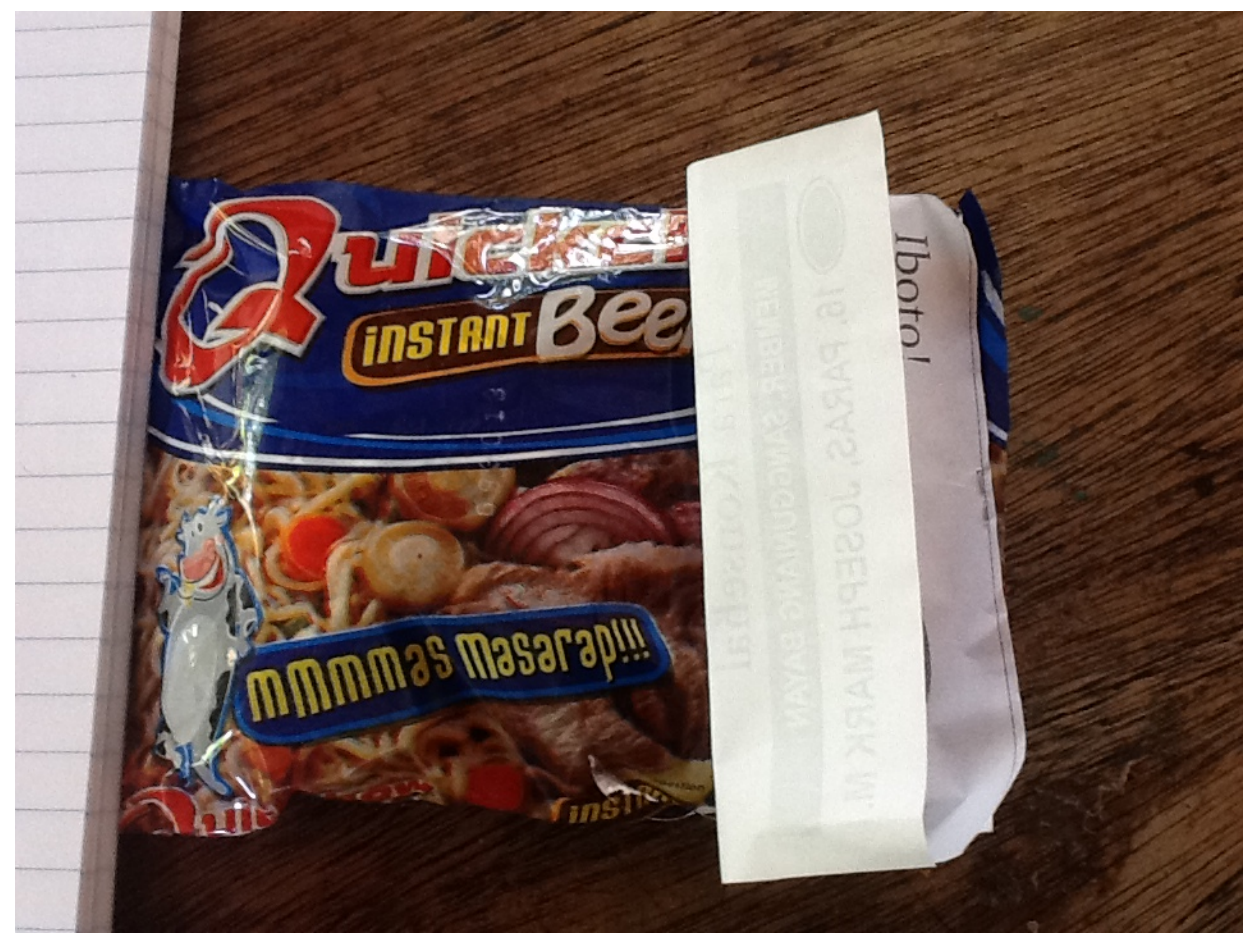

Appendix Figure 3: Candidate flyer attached to package of instant noodles. 


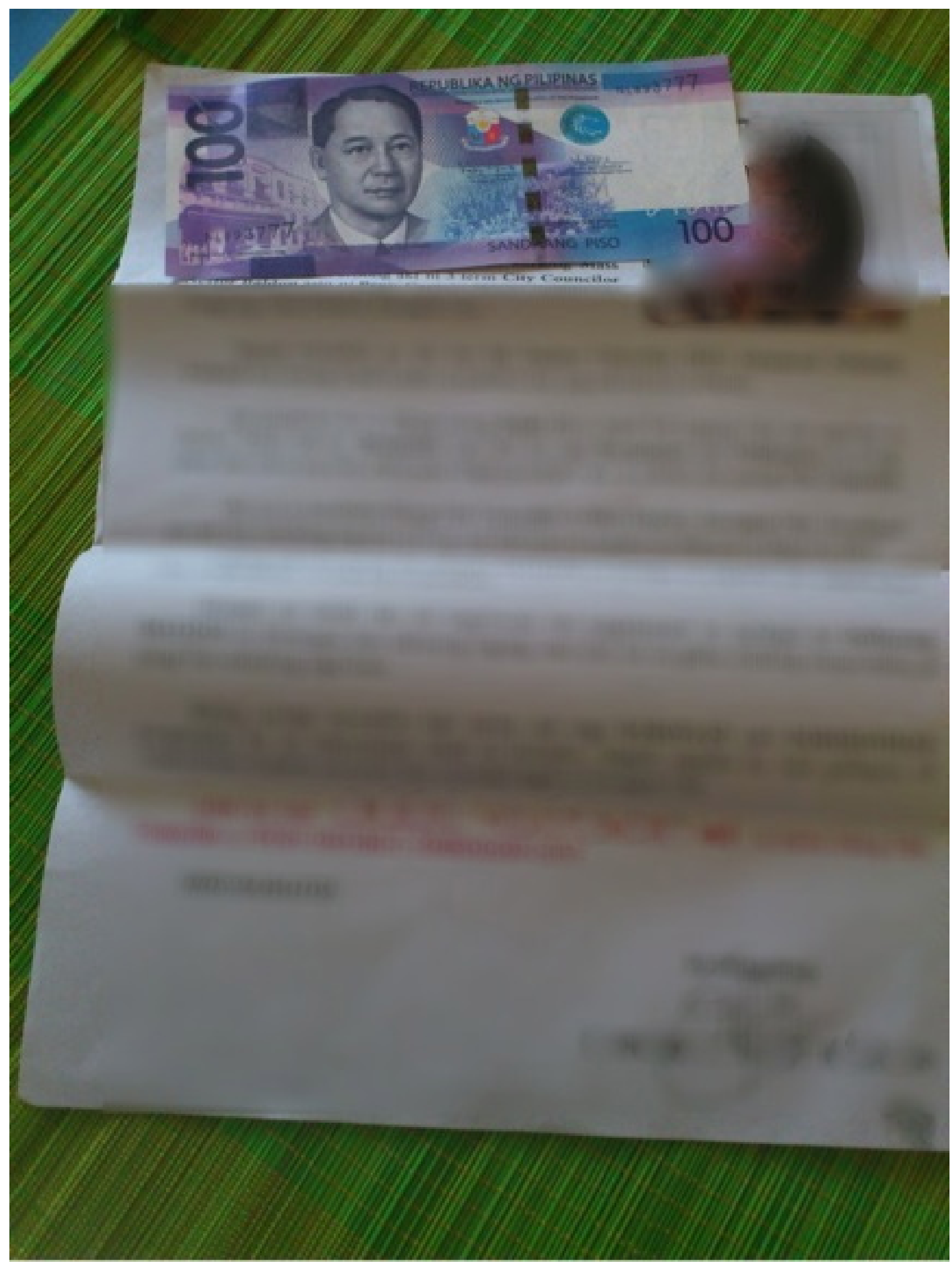

Appendix Figure 4: Money attached to a letter urging voters to support a particular candidate. 


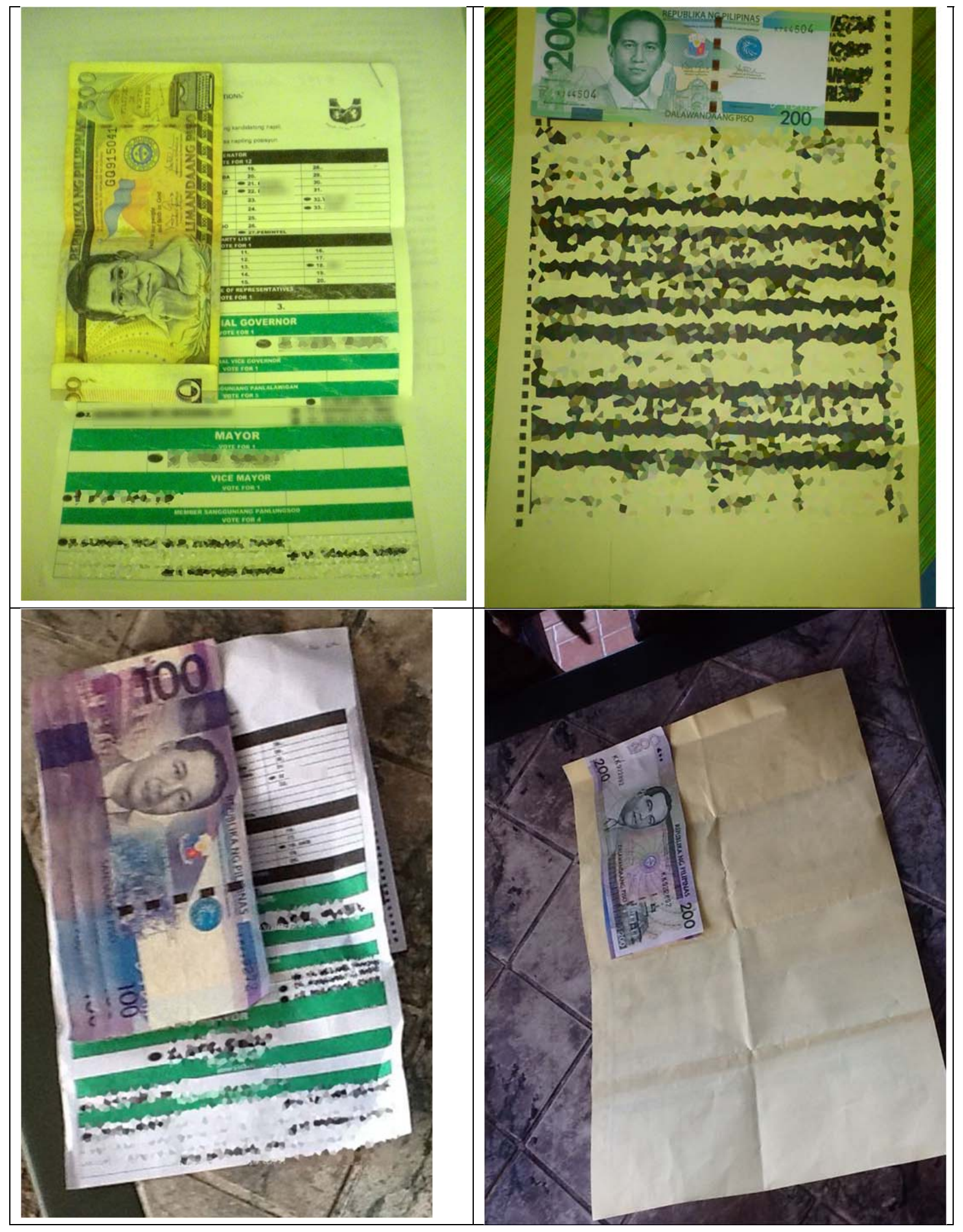

Appendix Figure 5: Sample ballots with money attached 


\section{Appendix B: Recruitment Script}

\section{In English:}

Hello, my name is . I am working with Innovations for Poverty Action along with the University of Michigan. We are researching voter education campaigns that can promote civic competence. We are asking you to participate because you are a resident of and a bona fide registered voter in Sorsogon City.

If you agree to be part of the research study, you will be asked to participate in a survey. We will ask questions about your voting behavior in the past and voting intentions for the upcoming May elections. We will also ask you to watch a 3-minute video clip relating to the elections.

While you may not receive a direct benefit from participating in this research, we hope that this study will contribute to improving the efficacy of voter education campaigns and promoting greater civic competence among Filipino.

Are you available to participate in our study?

(If asked) This interview will take approximately 30 minutes. If you do not have time to do the interview right now, we can arrange to come back at a later time.

\section{In Bicol:}

Dios marhay na adlaw, ako tabi si . Nagtatrabaho ako sa Innovations for Poverty Action kasabay san University of Michigan. Igwa tabi kami sin research tungkol sa voter education campaigns o mga kampanya para sa edukasyon kan mga botante. Iniimbitaran ka tabi namon magpartisipar sa research na ini, bilang registradong botante nan residente kan Sorsogon City.

Inhahagad tabi namon an partisipasyon nindo sa paagi san pagsimbag nindo sa saro na sarbey. An mga hapot sa sarbey tungkol sa mga hinimo mo kaugnay sa mga nakaaging eleksyon asin mga intensyon mo sa pag-boto niyan na maabot na eleksyon. Igwa man po kami sin halip-ot na video na ipapakita saimo na may kaugnayan sa eleksyon.

Maski ngani wara kami maipo-promisa sa imo na anuman na direktang benepisyo sa pagparticipar sa pagaadal na ini, inlalayon namon na makabulig an pag-aadal na ini para mapagayon asin mapamarhay pa an mga kampanya para sa edukasyon kan botanteng Pilipino.

May panahon ka tabi na mag-partisipar sa pag-aadal na ini?

(If asked) An interview na ini malawig sin mga 30 minutos. Kun wara ka tabi panahon sa interview na ini sa niyan, pwede man tabi kita mag-iskedyul sin iba na oras kun sano may panahon ka na. 


\section{Appendix C: Analysis of Attrition from Baseline to Endline}

To be included in the endline sample for analysis of a particular electoral outcome, a baseline respondent had to have: 1) completed the endline survey, 2) actually turned out to vote in the election, and 3) reported who they voted for in a given electoral race.

Appendix Table 1 presents regression estimates of the impact of the treatments on various measures of attrition from the endline sample for analysis. All regressions include the full set of control variables. For each dependent variable, the mean of the dependent variable in the control group is presented in the bottom row of the table.

In column 1, the dependent variable is an indicator for completion of the endline survey. In column 2, the dependent variable is an indicator for completion of the endline survey and turning out to vote. These outcomes are examined to shed light on any treatment-related differentials in preliminary stages of attrition. In the control group, the mean of the dependent variable is 0.966 and 0.938 respectively. As it turns out, the treatments have no large or statistically significant effects on these outcomes.

In columns 3 to 5, the dependent variables are indicators for completion of the endline survey, turning out to vote, and reporting one's vote for a particular electoral race (mayor, vice-mayor, or city council). These variables represent whether an individual in the baseline sample ends up being used in the endline analysis of voting for a particular electoral race. In the control group, the mean of the dependent variable for the mayor's race is 0.845 . The corresponding numbers for the vice-mayor and city council races are 0.852 and 0.897 respectively. This measure of attrition is also very similar across treatment conditions: for neither treatment is there a statistically significant difference vis-à-vis the control group.

In the remaining columns of the table, we examine two other related dependent variables: whether a baseline respondent ends up reporting his or her vote in all races (column 6), and in at least one race (columns 7). The promise treatments do not have any large or statistically significant effect on these attrition measures either.

All told, we conclude that attrition bias is not a worry in the empirical analyses of this paper. 


\section{Appendix Table 1: Impact of treatments on completion of voting reports at endline}

Ordinary least-squares regressions

Dependent variable: $\begin{gathered}\text { Completed } \\ \text { Endline Survey }\end{gathered}$

\section{Promise 1 treatment \\ ("Don't take money")}

Promise 2 treatment

("Take money, vote conscience")

Control variables

Observations

R-squared

Mean of dep. var. in control group
(1)

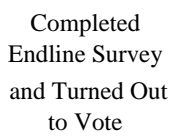

(2)

$\begin{array}{cc}-0.0120 & -0.0103 \\ (0.0162) & (0.0206) \\ -0.00529 & -0.00403 \\ (0.0151) & (0.0196)\end{array}$

$\mathrm{Y}$

883

0.057

0.966

\section{Y}

883

0.042

0.938

Completed
Endline Survey,
Turned Out
to Vote, and
Reported Vote
for Mayor

(3)

0.0180
$(0.0284)$
0.00688
$(0.0288)$

$Y$

883

0.070

0.845
Completed

Completed

Completed

Completed

Endline Survey, Endline Survey,
Turned Out

to Vote, and

to Vote, and

Reported Vote

for Vice-Mayor for City Council

(4)

(5)

$-0.00903$

(0.0296)

$-0.00756$

(0.0297)

-0.00521
$(0.0255)$
-0.00263
$(0.0250)$

$(0.0255)$

(0.0250)

Y

Y

Turned Out

to Vote, and

Reported Vote

for All Races

(6)

$\begin{array}{ll}-0.0112 & 0.00294 \\ (0.0328) & (0.0236) \\ 0.00295 & -0.00817 \\ (0.0322) & (0.0238)\end{array}$

$\mathrm{Y}$

883

$\begin{array}{cccc}883 & 883 & 883 & 883 \\ 0.039 & 0.037 & 0.060 & 0.037\end{array}$

0.852

0.897

0.801

0.911

*** $\mathrm{p}<0.01, * * \mathrm{p}<0.05, * \mathrm{p}<0.1$

Notes: Robust (Huber/White) standard errors in parentheses. Dependent variables are all indicator variables. Respondents randomized with equal (1/3) probability into the control group, Promise 1 treatment group, or Promise 2 treatment group. Control variables are listed in Panel A of Table 1 and were reported in baseline survey prior to treatment. 
Appendix Table 2: Impact of Treatments on Vote-Switching (regressions without control variables)

Ordinary least-squares regressions

\section{Dependent variable:}

Promise 1 treatment
("Don't take money")
Promise 2 treatment
("Take money, vote conscience")

Control variables

Observations

R-squared

\author{
Switched Vote in \\ Any Race
}

(1)

$\begin{array}{lccc}\beta_{1} & -0.0699 & \beta_{1 m} & 0.00969 \\ & (0.0429) & & (0.0279) \\ \beta_{2} & 0.0444 & \beta_{2 m} & 0.0406 \\ & (0.0426) & & (0.0297)\end{array}$

Switched Vote

for Vice-Mayor

(3)

$$
\begin{array}{lc}
\beta_{1 v} & -0.00802 \\
& (0.0359) \\
\beta_{2 v} & 0.0504 \\
& (0.0378)
\end{array}
$$

N

759

0.003

N
751
0.004

$\begin{array}{cc}\mathrm{N} & \mathrm{N} \\ & \\ 806 & 759 \\ 0.009 & 0.003\end{array}$

Switched Vote

for City Council

(4)

$$
\begin{array}{ll}
\beta_{1 c} & -0.0869 * * \\
& (0.0429) \\
\beta_{2 c} & 0.00601 \\
& (0.0437)
\end{array}
$$

${ }^{* * *} \mathrm{p}<0.01,{ }^{* *} \mathrm{p}<0.05, * \mathrm{p}<0.1$

Notes: Robust (Huber/White) standard errors in parentheses. Dependent variable in columns 1-10 equal to 1 if respondent switched his/her vote in the given race or set of races, 0 otherwise. Vote switching in mayor and vice-mayor races defined as voting for a candidate not receiving respondent's highest favorability rating in baseline (pre-election) survey. Vote switching in city council race defined as voting for a candidate not among the respondent's topfour highest-favored candidates in baseline survey. Respondents randomized with equal (1/3) probability into the control group, Promise 1 treatment group, or Promise 2 treatment group. Regressions include no control variables.

\section{Appendix Table 3: Tests of Theoretical Predictions (using coefficients from regressions without control variables)}

\section{A. Testing predictions of partially sophisticated theoretical case (within race, effects more negative for Promise 1 than Promise 2)}

$$
\begin{aligned}
& \text { Races pooled Mayor race Vice-mayor race City council race }
\end{aligned}
$$

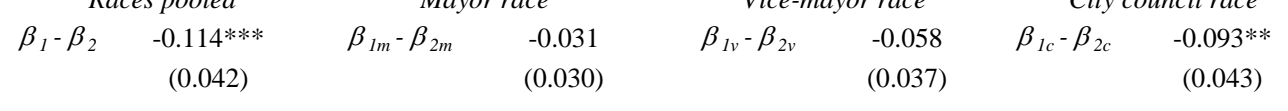

$$
\begin{aligned}
& \text { P-value of F-test: }\left(\beta_{1 m}-\beta_{2 m}=0\right) \&\left(\beta_{1 m}-\beta_{2 m}=0\right) \&\left(\beta_{1 m}-\beta_{2 m}=0\right) \quad 0.009
\end{aligned}
$$

\section{B. Testing prediction of differential effects across races (within promise, effects more negative for city council than in either mayor or vice-mayor races)}

$\begin{array}{lllll}\text { Comparing across races, for Promise 1: } & \beta_{1 c}-\beta_{1 m} & -0.097 * * & \beta_{1 c}-\beta_{1 v} & -0.079 \\ & & (0.049) & & (0.053) \\ \text { Comparing across races, for Promise 2: } & \beta_{2 c}-\beta_{2 m} & -0.035 & \beta_{2 c}-\beta_{2 v} & -0.044 \\ & & (0.051) & & (0.054)\end{array}$

P-value of F-test: $\left(\beta_{1 c}-\beta_{1 m}=0\right) \&\left(\beta_{1 c}-\beta_{1 v}=0\right) \&\left(\beta_{2 c}-\beta_{2 m}=0\right) \&\left(\beta_{2 c}-\beta_{2 v}=0\right)$

C. All theoretical predictions in A. and B. combined

$$
\begin{aligned}
& \text { P-value of F-test: }\left(\beta_{1 m}-\beta_{2 m}=0\right) \&\left(\beta_{1 m}-\beta_{2 m}=0\right) \&\left(\beta_{1 m}-\beta_{2 m}=0\right) \\
& \&\left(\beta_{1 c}-\beta_{1 m}=0\right) \&\left(\beta_{1 c}-\beta_{1 v}=0\right) \&\left(\beta_{2 c}-\beta_{2 m}=0\right) \&\left(\beta_{2 c}-\beta_{2 v}=0\right)
\end{aligned}
$$

